University of Louisville

ThinkIR: The University of Louisville's Institutional Repository

Electronic Theses and Dissertations

$12-2017$

\title{
A comparison of mean age theory and residence time distributions in mixed systems.
}

Nolan Theaker

University of Louisville

Follow this and additional works at: https://ir.library.louisville.edu/etd

Part of the Other Chemical Engineering Commons

\section{Recommended Citation}

Theaker, Nolan, "A comparison of mean age theory and residence time distributions in mixed systems." (2017). Electronic Theses and Dissertations. Paper 2811.

https://doi.org/10.18297/etd/2811

This Master's Thesis is brought to you for free and open access by ThinkIR: The University of Louisville's Institutional Repository. It has been accepted for inclusion in Electronic Theses and Dissertations by an authorized administrator of ThinkIR: The University of Louisville's Institutional Repository. This title appears here courtesy of the author, who has retained all other copyrights. For more information, please contact thinkir@louisville.edu. 


\title{
A COMPARISON OF MEAN AGE THEORY AND RESIDENCE TIME DISTRIBUTIONS IN MIXED SYSTEMS
}

\author{
By \\ Nolan L Theaker \\ B.S. Chemical Engineering, University of Louisville, 2016
}

A Thesis Submitted to the Faculty of the J. B. Speed School of Engineering of the University of Louisville in Partial Fulfillment of the Requirements of the Degree of

\author{
Master of Engineering \\ In Chemical Engineering \\ Department of Chemical Engineering \\ University of Louisville \\ Louisville, KY
}

November 2017 



\title{
A COMPARISON OF MEAN AGE THEORY AND RESIDENCE TIME DISTRIBUTIONS IN MIXED SYSTEMS
}

\author{
Submitted by: \\ Nolan Theaker
}

A Thesis Approved on

November $28^{\text {th }}, 2017$

by the following Reading and Examination Committee

Dr. Eric Berson, Thesis Director

Dr. Gerold Willing

Dr. Yongsheng Lian 


\section{ACKOWLEDGEMNTS}

First, I would like to thank my wife, Emily, for motivating and supporting me through this work. She continuously pushed me towards completing this accomplishment, without which I may not have finished.

Dr. Berson's advice on everything involving this project, from advice about CFD, supercomputer help, and writing. His help has furthered the work and myself as a researcher and human being.

Javad Hashemi's knowledge of the erratic nature of CFD and his willingness to help in anything that I needed. 


\begin{abstract}
A comparison between mean age theory and conventional residence time distributions over a range of quantified mixing levels was conducted using computational fluid dynamics (CFD). The system was a stirred tubular reactor. The model was validated by comparing computationally derived RTD curves with experimentally obtained RTD curves, with quantified differences less than 3\%. Mixing was quantified using the Tanksin-Series model. Mixing levels were set by varying flow rate and impeller rpm. Mean age distributions at the outlet, where experimental RTD's were measured, were very narrow for all levels of mixing studied. RTD's showed expected characteristics; a wider distribution and long decay for high mixing cases and a narrow distribution centered around the mean time for cases approaching plug flow. Mean age distributions remained substantially narrower than RTD's. RTD's and mean age distributions were measured at several locations along the length of the reactor to determine changes in characteristics of each along the reactor. RTD's and mean age distributions exhibited a narrowing along the length of the reactor, indicating a transition from well-mixed characteristics near the
\end{abstract}


entrance to plug flow behavior near the exit. Differences in the mean age and mean residence time at the outlet increased from $7 \%$ at low mixing to $30 \%$ at high mixing. Ultimately, this study showed mean age distributions are not comparable to RTD curves over a range of mixing levels. Mean age theory can provide age of material throughout an entire system volume, while RTD's provide a distribution only at a single measurable location. 


\section{TABLE OF CONTENTS}

$\underline{\text { Page }}$

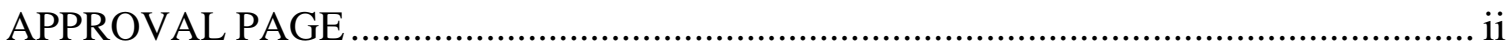

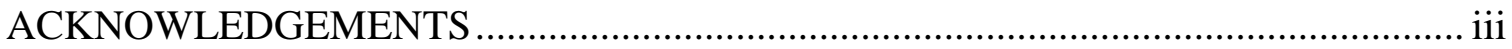

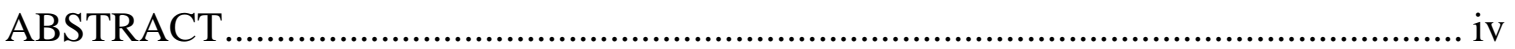

LIST OF TABLES ……............................................................................................... vii

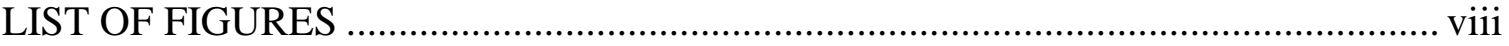

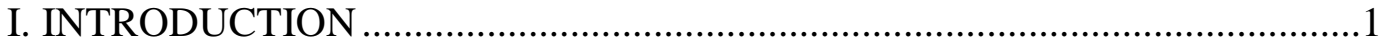

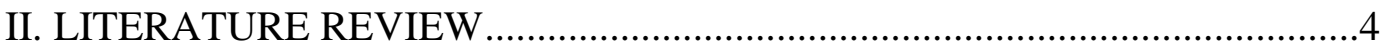

A. Residence Time and Mean Age …………………….........................

B. Characterization of Mixing ................................................................11

C. Applications of Mean Age ..................................................................15

D. Computational Fluid Dynamics ……………………….....................22

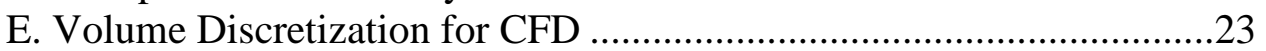

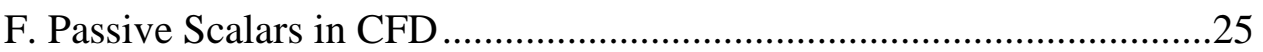

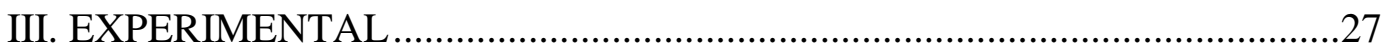

A. Experimental Workplan .................................................................2.

B. Materials - Software and Hardware .................................................28

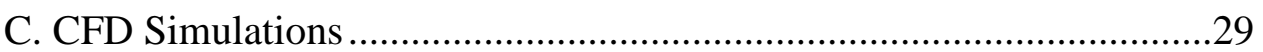

1. Defining the Geometric Volume.................................................29

2. Geometry Construction ..............................................................32

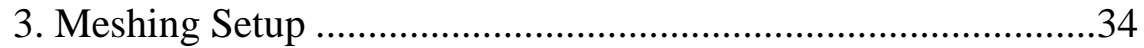

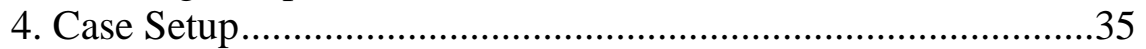

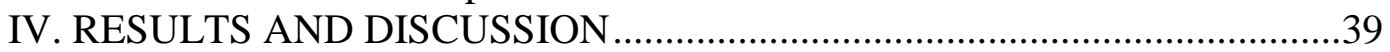

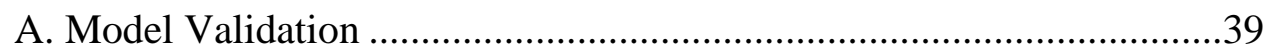

B. RTD and Mean Age Measurements at Different Levels of Mixing......41

C. Comparison of Interior RTD's and Mean Age Curves …………….......52

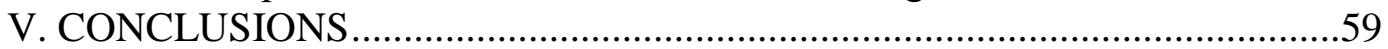

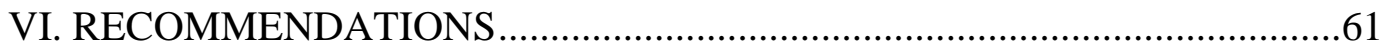

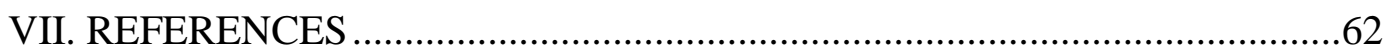

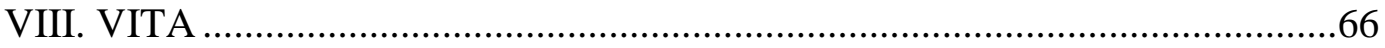




\section{LIST OF TABLES}

Figure

$\underline{\text { Page }}$

I - DIMENSIONS OF STIRRERS USED IN ZHANG ET AL (1990)

II - MESH SENSITIVITY ANALYSIS VALUES

III - CASE SETUPS FOR N DISTRIBUTION WITH COMPUTATIONAL

ITERATIONS .

IV - COMPARISON OF MEAN RESIDENCE TIME AND AVERAGE OUTLET

MEAN AGE. 


\section{LIST OF FIGURES}

Figure

1 - STEP INPUT RTD'S FO FLOW SYSTEMS INSIDE VESSELS …………………....7

2 - PULSE INPUTS OF A TRACER COMPOUND IN A C CURVE ...............................8

3 - GRAPHS OF RTD'S OF VARYING LEVELS OF MIXING ………......................12

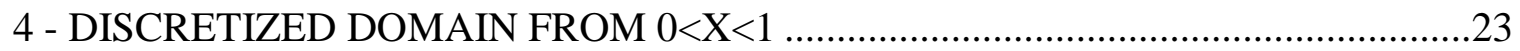

5 - EXPERIMENTAL SCHEMATIC FOR ZHANG ET AL (1990)................................29

6 - TYPES OF STIRRERS USED IN ZHANG ET AL (1990)..........................................31

7 - GEOMETRIC MODEL OF SYSTEM. TRACER INJECTION OCCURRED AT THE

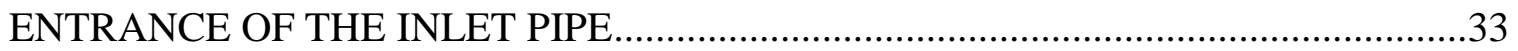

8 - QUALITATIVE VALIDATION OF RTD'S............................................................. 40

9 - QUANTITATIVE VALIDATION OF MODEL AND RTD METHOD USING L/Nd40 10 - DIMENSIONLESS RTD CURVES OVER A RANGE OF MIXING QUANTIFIED BY THE TANKS-IN-SERIES MODEL FOR N BETWEEN (A) 3.1 AND 8.9, AND (B)

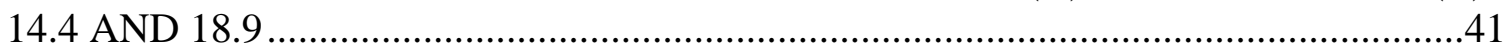

11 - (A) OUTLET MEAN AGE FREQUENCY AND (B) RTD. $(\mathrm{N}=18.9) \ldots \ldots \ldots \ldots \ldots \ldots . .43$

12 - (A) OUTLET MEAN AGE FREQUENCY AND (B) RTD. $(\mathrm{N}=17.5) \ldots \ldots \ldots \ldots \ldots \ldots . .44$

13 - (A) OUTLET MEAN AGE FREQUENCY AND (B) RTD. $(\mathrm{N}=15.0) \ldots \ldots \ldots \ldots \ldots \ldots . . .44$

14 - (A) OUTLET MEAN AGE FREQUENCY AND (B) RTD. $(\mathrm{N}=13.3) \ldots \ldots \ldots \ldots \ldots \ldots . . .45$

15 - (A) OUTLET MEAN AGE FREQUENCY AND (B) RTD. $(\mathrm{N}=8.9) \ldots \ldots \ldots \ldots \ldots \ldots \ldots . .45$

16 - (A) OUTLET MEAN AGE FREQUENCY AND (B) RTD. $(\mathrm{N}=6.5) \ldots \ldots \ldots \ldots \ldots \ldots \ldots . . .46$

17 - (A) OUTLET MEAN AGE FREQUENCY AND (B) RTD. $(\mathrm{N}=5.0) \ldots \ldots \ldots \ldots \ldots \ldots \ldots . .46$

18 - (A) OUTLET MEAN AGE FREQUENCY AND (B) RTD. $(\mathrm{N}=3.1) \ldots \ldots \ldots \ldots \ldots \ldots \ldots . .47$

19 - CONTOUR OF MEAN AGE AT OUTLET OF SYSTEM …………………..........48

20 - A CONTOUR OF VELOCITY MAGNITUDE ACROSS THE LENGTH OF THE

VESSEL ..................................................................................................5

21 - CONTOUR OF MEAN AGE ALONG THE LENGTH OF THE SYSTEM AT N=550

22 - CONTOUR OF MEAN AGE ALONG THE LENGTH OF THE SYSTEM AT

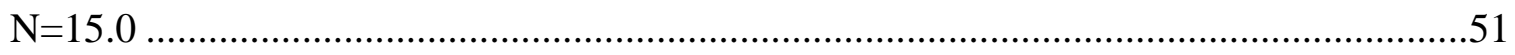

23 - LOCATION OF INTERMEDIATE PLANE FOR RTD AND MEAN AGE

MEASUREMENTS ……………………………………..............................52

24 - (A) RTD AND (B) MEAN AGE CURVE OF HIGHEST PLANE OF N=5.0

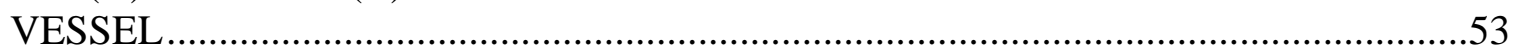

25 - (A) RTD AND (B) MEAN AGE CURVE OF MIDDLE PLANE OF N=5.0 VESSEL53

26 - (A) RTD AND (B) MEAN AGE CURVE OF LOWEST PLANE OF N=5.0

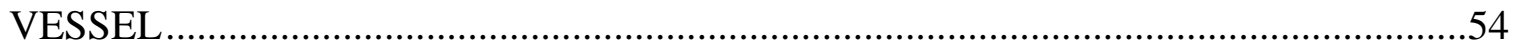

27 - COMPARISON OF ZOOMED SECTION OF THE MEAN AGE CURVE ALONG

THE LENGTH OF THE N=5.0 VESSEL ………………....................................................54

28 - (A) RTD AND (B) MEAN AGE CURVE OF HIGHEST PLANE OF N=18.9

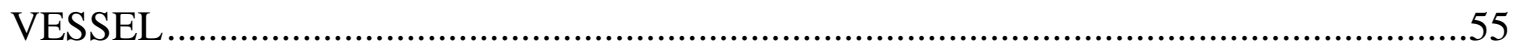

29 - (A) RTD AND (B) MEAN AGE CURVE OF MIDDLE PLANE OF N=18.9

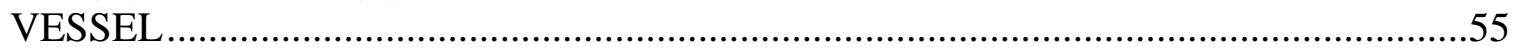

$\underline{\text { Figure }}$ Page

30 - (A) RTD AND (B) MEAN AGE CURVE OF LOWEST PLANE OF N=18.9 VESSEL 
31 - COMPARISON OF ZOOMED SECTION OF THE MEAN AGE CURVE ALONG

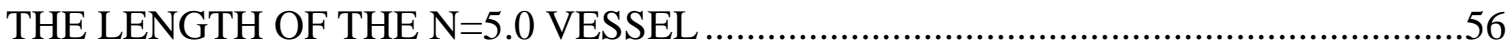




\section{INTRODUCTION}

Variation in mixing is critical for engineering processes, particularly reaction engineering, and an accurate method for characterizing the mixing is equally critical. Residence time distributions (RTD's), which indicate tracer paths through a continuous system, have historically been widely used to characterize mixing, However, a RTD only gives a partial picture of mixing, as it fails to recognize the location of reactor dead zones, short-circuiting, and other mixing inefficiencies. With increased computing power, the concept of mean age to characterize mixing has advanced. Mean age is the average time of all material passing through a given location in a continuous system, and provides a complete spatial distribution of age, allowing one to analyze mixing at any point inside of a reactor. This was first introduced by Danckwerts (1959), but the lack of either a practical way to measure tracer throughout a system volume or compute the mean age

distribution prevented using this method. Due to both advances in widely accessible computing power and increasingly accurate computational fluid dynamics (CFD) software, computing complete spatial distributions of mean age is now readily attainable 
as demonstrated in publications such as Baleo and Cloirec (2000), Liu and Tilton (2010), and Russ and Berson (2016).

Mean age is generally considered to be computationally and descriptively advantageous over residence time distributions. Residence time distributions require transient solutions with much longer compute times than steady state solutions, especially considering the total time for all tracer to exit the system may be orders of magnitude longer than the mean time. On the other hand, mean age theory allows for a steady state solution, reducing computational costs significantly. Additionally, mean age computations provide a spatial distribution of age throughout an entire system, whereas residence time distributions are only determined at a discrete location, typically the outlet. This allows a further examination of local mixing in fluid systems, granting a clearer view of mixing phenomena such as short-circuiting and dead zones.

The mean residence time for a give system as determined from both residence time distributions and mean age theory should be equal. However, the shape of the distributions of residence time and mean age at the outlet have never been compared against one another. The curves are expected to agree for a plug flow system, as the fluid moves as a single slug, producing a uniform mean time across the flow plane. However, the well-mixed case is expected to have divergence between the two distributions. As mixing further increases, nearby fluid will continuously transfer fluid of different ages between one another, yielding an aggregation to the mean in areas of high mixing. 


\section{Experimental Objectives}

1. Validate a computational model by comparing experimentally determined RTDs with computationally determined RTDs that mimic the experimental system.

2. Compare residence time distributions with mean age in systems with varying levels of mixing, where mixing is characterized by the number of stirred tanks in series model.

3. Evaluate mean age and residence time distribution curves at various stages of the reactor to examine how each progress along the reactor length. 


\section{LITERATURE REVIEW}

\section{A. Residence Time and Mean Age}

Residence time was first introduced as a concept by Danckwerts, ushering in a new method for dealing with mixing(Danckwerts 1953). Before that research, a vessel was either approximated as plug flow (unmixed) or ideal mixing (CSTR), with very little definition to anything in between those extremes. Danckwerts used a tracer injection to test the mixing of the reactor, ultimately in the hopes of quantifying levels of mixing. This resulted in distributions of tracer output that could be used to get a mixing profile. Within this original work, he performed experiments on pipelines, packed beds, and stirred tank mixing to show how the distributions can be characterized. Additionally, he laid out equations for which a mean time and variance of the distribution could be easily calculated. However, this tracer method could only be measured at a single point (outlet), and could not accurately describe the mixing in different regions of a vessel. 
Tracers have been used in the form of a conductive salt $(\mathrm{KCl})$ (Richter et al (2015)), a flammable gas (butane) (Baleo and Cloirec, 2000), a well-defined and controlled chemical reaction (Liu and Tilton, 2010), or other various methods. To be an effective tracer, the compound or reaction must not impede or alter the flow characteristics and be easily measured at a plane, such as the conductivity of a solution with injected $\mathrm{KCl}$ salt.

The residence time distribution function is defined as the time each particle of a tracer remained in the system, where plug flow functions would have a distribution mirroring the Dirac-Delta function, where all material enters and leaves simultaneously. Additionally, a residence time distribution of a well-mixed system will appear as an exponential decay function. The RTD is defined by several functions, namely $E(t)$, where:

$$
E(t)=\frac{C(t)}{\int_{0}^{\infty} c(t) d t}
$$

The $\mathrm{E}(\mathrm{t})$ function is in its nature a function of time. However, by expressing time in dimensionless form such as:

$$
\theta=\frac{\text { time }}{\text { mean time }\left(t_{m}\right)}
$$


A dimensionless form of the $\mathrm{E}$ curve is found. To compare separate systems utilizing these dimensionless terms, a plot of $\mathrm{E}(\theta)$ vs $\theta$ may be used, where $\tau$ is space-time.

$$
E(\theta)=\tau E(t)
$$

The first moment of the distribution function describes the mean of the function, $\mathrm{t}_{\mathrm{m}}$ as:

$$
t_{m}=\int_{0}^{\infty} t E(t) d t
$$

This should imply that the variance is related to the second moment of the distribution function, of which:

$$
\sigma^{2}=\int_{0}^{\infty}\left(t-t_{m}\right)^{2} E(t) d t
$$

Residence time distributions may be gathered in two distinct ways, as a step input or a pulse input. For the step input, a continuous flow of a tracer compound in introduced to the system, and a measure of flow of the compound is monitored until the flow leaving a vessel is equivalent to the flow of tracer entering. Sample RTD curves from this type of flow are found in Figures 2.1, ranging from ideal plug flow to perfectly mixed. An example of a step input RTD being used in modern research is of the work of Klutz et 
al.(Klutz et al. 2015) in designing a new reactor system to reduce mixing from typical straight tubular reactors.
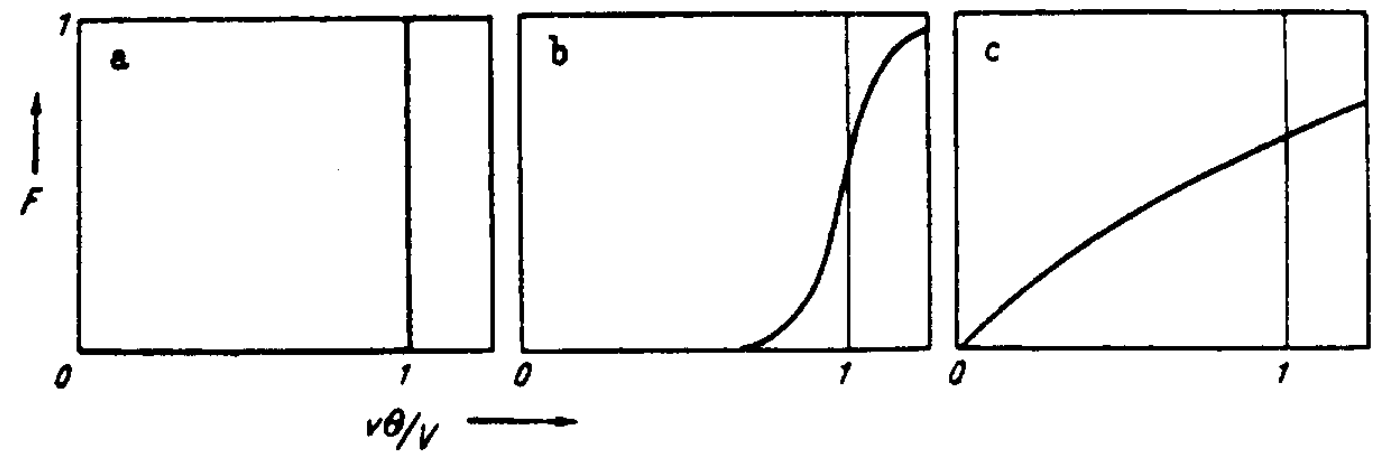

FIGURE 1. STEP INPUT RTD’S FO FLOW SYSTEMS INSIDE VESSELS.

As shown in Figure 1, the $\mathrm{x}$-axis of the plot is of dimensionless time of the form of the current time divided by the mean residence time. The y-axis of the graph is a dimensionless concentration term derived from the current flow of material out divided by the total amount of tracer flowing into the system. Plot a) is of a perfect plug flow system, c) is one of perfect mixing, and b) is somewhat mixed.

RTDs may be measured from pulse inputs or step inputs, with a pulse input being an instantaneous injection of a tracer compound. This compound is measured at the outlet of the vessel or fluid system and tracked until a certain amount or all the tracer substance is recovered. Sample residence time distributions of pulse inputs are found below in Figure 2. Applications of pulse inputs can be found in the works of Sugiharto et al. with radiotracer pulse(2009). 


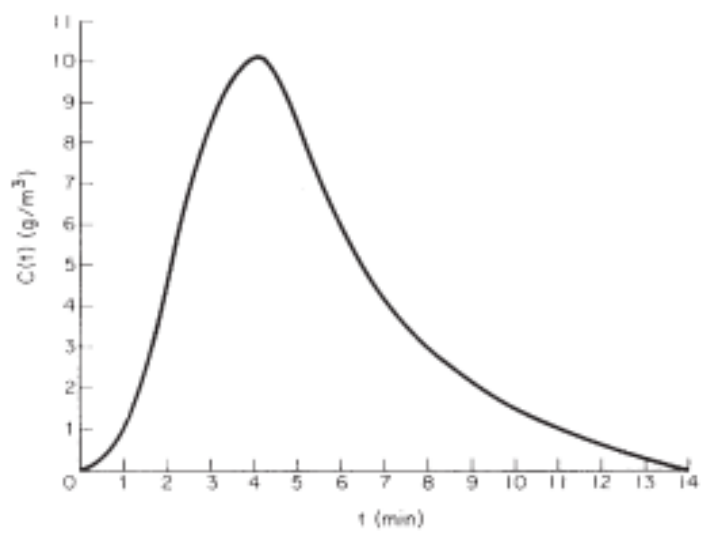

FIGURE 2. PULSE INPUTS OF A TRACER COMPOUND IN A C CURVE. (Fogler 2006).

The step residence time distribution method does largely remove the effects of an imperfect injection of the tracer, as the pulse method requires in theory a Dirac-Delta method of injection, not possible in real terms. However, the pulse method may give a higher accuracy on the measurement of the tracer, as very slight differences in the tracer compound are harder to detect near the input level, where slight changes in the concentration of the tracer may be easily measured at lower concentrations.

Due to the spatial drawbacks of residence time, Danckwerts laid out groundwork into another field of mixing with his paper five years later, characterizing a localized residence time for sections of a vessel, which he labeled as "age", to further explore stagnant regions of fluid in the vessel(Danckwerts 1959). These areas would be defined by relatively high age in the area, but this method of finding the age of particles in any given area was found to be significantly more difficult to achieve than the residence time distribution. Ultimately, Danckwerts' goal was to develop a degree of mixing parameter, 
which was continued by the work of Zwietering(1959). However, work was done by Spalding, to give a first formal equation of age as:

$$
a(x)=\frac{\int_{0}^{\infty} t C\left(x_{2} t\right) d t}{\int_{0}^{\infty} c\left(x_{2} t\right) d t}
$$

where $C(x, t)$ is the concentration of a scalar at position $x$ and time $t$ (Spalding 1958). This would set the groundwork for Sandberg, to develop a transport equation for age, rooted in the advective-diffusion equation(Sandberg 1981).

$$
\frac{\partial C}{\partial t}+\nabla \cdot(u C)=\nabla \cdot(D \nabla C)
$$

By replacing the concentration of a scalar term with the definition of age, where the differential of age with respect to time is one; (further derivation between Equations 7 and 8 may be found in Liu and Tilton (2010).

$$
\nabla \cdot(u a)=\nabla \cdot(D \nabla a)+1
$$

For each unit of time that passes in a system, one unit of age is added. In cases where mass flow of fluid is used as the convective transport method instead of velocity (ANSYS 
Fluent), multiplication of all terms by the density of the fluid is required, yielding a scalar value of the density of the species of interest rather than of one.

For incompressible flow, steady state, and neglecting diffusive transport of age, the transport equation of age reduces to:

$$
u_{i} \frac{\partial a}{\partial x_{i}}=1
$$

Boundary conditions for this age function follow similarly with the concentration of a scalar boundary conditions(Liu and Tilton 2010).

Inlet:

$$
a=0
$$

Outlet: $\quad \frac{\partial a}{\partial x_{i}}=0$

These boundary conditions show that at the inlet, all fluid is considered new to the system, while age is not considered past the outlet. Since the transport equation has three differential components, an additional boundary condition is required.

Wall: $\quad \frac{\partial a}{\partial x_{i}}=0$ 
This condition follows along the zero-flux condition, where at the wall no particle of fluid will be moving in any direction, showing that the age should have zero change with respect to position on those surfaces.

Due to the complexity of taking age measurements throughout a vessel simultaneously, the transport equation for age was not validated until the growth of computation fluid dynamics, where age could be calculated throughout a vessel. The work that first validated this mean-age model was Baleo and le Cloirec, which used a turbulent flow of air and a butane tracer to move through a pipe which had multiple contractions and expansions(Baleo and Le Cloirec 2000). They could test the age of the gas at multiple places along the pipeline and with CFD, and showed convergence between stimulation and experimental values within 5\%. This paved the way for computationally determining mean age throughout any point in a vessel using Equation (7).

\section{B. Characterization of Mixing}

Danckwerts' showed that mixing is variable, not limited to the approximations of plug flow or perfectly mixed, but did not fully quantify how mixed a system was(Danckwerts 1953). Models to quantify levels of mixing came later, in the form of tanks-in-series and dispersion models. In the case of the tanks-in-series model, a single vessel or reactor is assumed to be described by a number of perfectly mixed tanks in series $(\mathrm{N})$, where a perfectly mixed system will require one tank, and a plug flow system will require an infinite number of tanks. This model does allow for a numeric comparison 
between the mixing of systems, as lower values indicate higher levels of mixing. The earliest readily available mention of this model was with the work of Kusunoki(1965).

Ultimately, the theory is based upon residence time distributions, specifically the moments of the distributions, with the calculation of the number of stirred tanks in series being equivalent to:

$$
N=\frac{t_{m}^{2}}{\sigma^{2}}
$$

where $t_{\mathrm{m}}$ is the mean residence time for a vessel and $\sigma^{2}$ is the variance of the distribution function(Levenspiel 1999). A figure of these varying levels of mixing as drawn as RTD curves is shown in Figure 3, with varying levels of mixing characterized by the tanks-inseries model with the number of tanks listed $(\mathrm{N})$.

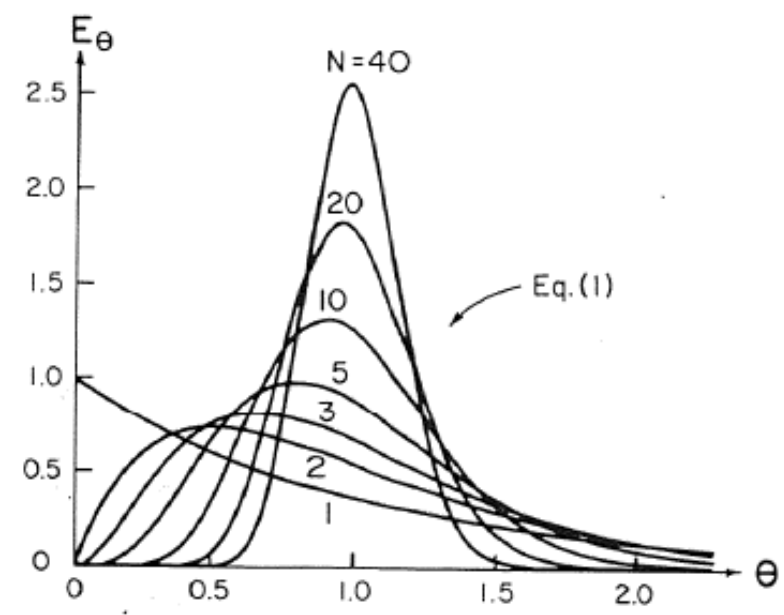

FIGURE 3. GRAPHS OF RTD'S OF VARYING LEVELS OF MIXING. (Zhang et al. 1990). 
As seen, and as predicted from the behavior of mixing systems of chemical reactions, increasing numbers of stirred tanks in series approximates plug flow behaviors. This is evident in a Levenspiel plot, where plug flow reactors volumes are evaluated as integrations underneath the curve while CSTR's are evaluated as a product of the operating point. As more CSTRs are placed in series, a closer approximation to the integration under the curve is realized, with an infinite number of stirred tanks in series being equivalent to the behavior of a plug flow reactor.

This theory is found used in literature for many different application and across a wide variety of times. For instance, Schlossmacher et al. used the model to describe mixing inside of blood vessels as a test to find how quickly a tracer is diluted and removed through the body(Schlossmacher, Weinstein et al. 1967). Additionally, researchers into the $21^{\text {st }}$ century have continued using this model to characterize mixing, such as Katoh et al. in mixing within gas separation membranes(Katoh et al. 2011).

Dispersion models are often used to characterize tubular vessels, as the dispersion parameters that define non-ideal mixing can identify and describe radial flow in the tubular vessel along the length of the vessel. Because of the added driving force from a concentration difference in the radial direction, the tracer compound will begin to drift towards sections of the flow profile lacking the tracer, yielding a radial flow. As the fluid begins to move radially, the distribution of residence times broadens from the DiracDelta function which models ideal plug flow behavior. A larger dispersive coefficient is indicative of increased mixing within a system. Additionally, as a concentration gradient forms along the radial direction, dispersive mixing will increase along the length of the vessel(Fogler 2006). The dispersion model of mixing gives useful parameters that 
describe the fluid flow through the reactor. This contrasts with the number of stirred tanks in series model, as the tanks model fails to describe how the fluid is being mixed; simply that it is.

The dispersion coefficients may be found in one of two ways. The first way, experimentally, utilizes the RTD curve to find the Peclet number, of which can then be converted into a dispersive coefficient. Equation 11 shows the correlation between the RTD curve and the Peclet number $(\mathrm{Pe})$ utilizing the mean residence time ${ }^{\mathrm{TM}}$ and the variance of the distribution $\left(\sigma^{2}\right)$.

$$
\frac{\sigma^{2}}{t_{m}^{2}}=\frac{2}{P e}-\frac{2}{P e^{2}}\left(1-e^{-P e}\right)
$$

After determining the Peclet number using Equation (13), the dispersion coefficient, D, can be determined from Equation (14), where U is the superficial velocity of the fluid and $\mathrm{L}$ is the length of the tubular section.

$$
P e=\frac{U L}{D}
$$

Nautiyal et al. applied the dispersion model to calculate dispersion coefficients for gaseous mixing, and Abdulmohsin and Al-Dahhan applied the model to characterize mixing of gases within packed pebble-bed reactor (Abdulmohsin and Al-Dahhan 2016, 
Nautiyal et al. 2017). These researchers used dispersion modeling to show improvement in radial flow distributions in tubular reactors, with the goal of increasing mixing.

\section{Applications of Mean Age}

Sandberg (1981) validated the mean age transport equation mainly for gases, specifically in the fields of HVAC and ventilation. Further examples of mean age theory used in ventilation and gas diffusion occurred in the works of Bartak et al. and Chanteloup and Mirade(Bartak et al. 2002, Chanteloup and Mirade 2009). With experimental data difficult to gather in the fields of ventilation, computational fluid dynamics was used extensively. CFD allowed a relatively easy method of calculating the spatial distribution of age, allowing for better construction and tuning of ventilations systems to avoid large dead zones of flowing gases.

Liu and Tilton used computational modeling to further validate the mean age of liquids in a vessel, with variation from experimental being less than 5\%(Liu and Tilton 2010). Additionally, they characterized the age as a distribution function, where the first moment of that function corresponds to mean age. The second moment of the age distribution function is therefore related to the variance of the age function. Liu and Tilton also showed the value in calculation of mean age via CFD by displaying spatial distributions of age.

The following year, Liu developed additional examples of mean age applications, specifically on a continuous flowing system, where a calculation of a degree of mixing parameter was performed(Liu 2011). Degrees of mixing have been the ultimate goal of 
many mixing researchers, but without the ability to calculate age of a fluid inside of a vessel, ultimately approximations would have to be made. Computational fluid dynamics ultimately allowed researchers to effectively and accurately calculate the internal age function set out first by Danckwerts and Zwietering. The method utilized the spatial distribution of age and the variance of the age frequency function to evaluate mixing. Liu theorized that this calculation would be particularly useful in non-ideal stirred tanks.

Liu mapped spatial distributions of age across a stirred tank, permitting the evaluation of critical parameters in a stirred tank system for mean age, of which impeller rotational speed and impeller to tank diameter were considered(Liu 2011). Additionally, the study showed the improvements in computational cost made from using mean age theory versus a standard tracer experiment, where mean age may be calculated using steady state flow conditions where the use of a tracer by necessity requires transient calculations to be made. Liu also validated the work on the stirred tank by unsteady state calculations of tracer injections performed experimentally with high agreement in residence time values.

Liu went further in developing a method of calculating a variance for mean age systems based upon the mean residence time of the system(Liu 2012). This variance allows for a further explanation of degrees of mixing by utilizing the quicker method of mean age calculations. The system used was a continuous flow stirred tank reactor. The feed rate to the reactor was varied to achieve different mean residence times. The variance of age compared with mean residence time showed that at low mean residence times (lower mixing), the variance in age rose among the five cases used. At high mean residence times, however, the variances exponentially moved towards one. 
Russ and Berson utilized multiphase mean age, a derivative of the mean age theory, in characterizing fluid flow for an oil, water, and air system through pipelines(Russ and Berson 2016). The theory was useful in characterizing the profiles of age for each independent phase a certain distance down the length of the pipe. This work showed that mean age could be applied to individual phases within a flow as well as the aggregate, permitting further investigation into the applicability of mean age theory in

more systems. In this work, the comparison between mean age of outlet faces and residence time distributions was introduced, comparing that the mean of each are approximately equivalent, yet the variance of each curve further apart.

\section{Computational Fluid Dynamics}

CFD is a simulation technique which utilizes numerical solutions to solve the governing equation of fluid flow in systems of interest. CFD usage is growing in amount of applications and people in the field, with application ranging from aerodynamics of fins, swimsuit optimization, and energy production, just to name a few of the vast number of fields possible. With the development of smaller, faster, and cheaper computers, higher levels of calculations can be made to improve accuracy and reduce overall computational time. Through application of the necessary physics and chemistry of the materials of interest in a system, the software can generate:

- Velocity profiles of liquids and gases

- Temperature and concentration profiles

- Path lines of movement for moving fluid or bodies 
- Chemical reaction data

- Profiles of movement and drag about stationary objects

CFD also allows the visualization of fluid flows in regions where visualization may be impossible, either due to enclosures or size. Additionally, properties of the fluid in these points where monitoring is impossible may be determined, permitting higher sensitivity in design of systems.

CFD is a relatively old technique in terms of computers, as some of the first simulations were Kopal computing supersonic flows. The computer used in this case was a relatively primitive, yet still able to calculate the differential equations numerically(Kopal 1947). CFD began more widespread use with accuracy in the 1960's with the multiple works of Blottner utilizing CFD to examine nonequilibrium boundary layers in air in high velocity conditions(Blottner 1964, Blottner et al. 1964). Newer techniques began to be added to CFD, such as supersonic and viscous flows, forcing the adoption of the Navier-Stokes equations and transient techniques to be added(Hall, Eshcenroeder et al. 1962). This elevated CFD methods into a resemblance of today.

CFD can be broken up into 3 distinct sections; preprocessing, simulation, and postprocessing. Preprocessing involves the construction of the geometric model, for which programs such as ANSYS Design Modeler, SOLIDWORKS, and GAMBIT have been widely used. This geometric model will be made up of volumes of flow regions and surfaces that enclose the fluid region of interest. These surfaces may be made up of walls around the system, impellers, fluid inlets designating the start of the computational flow field, and outlets designating the end of the field. Any specific regions, be they volumes or surfaces, may be specifically defined at this point allowing the user to extract data for 
those specific regions. Any volume or surface that requires a specification of a condition must be labeled at this point, such as the inlet and outlet. Geometric models of fluid systems for CFD analysis may be two dimensional or three dimensional, depending on the complexity of the system. Two dimensional models vastly reduce computational cost; however, they can oversimplify a system and yield a misleading flow field. Rather than defined surface of boundary conditions for a two-dimensional system, walls, inlets, and outlets are defined by edges.

After the construction of the geometric model of the fluid system of interest, a computation mesh must be constructed to form the elements by which the calculation can occur. In some software packages, such as DMT, an automated mesh of equal volume cells is constructed; however, some regions of the fluid regions may require more sensitivity than others. For ANSYS Fluent, a mesh must be created by the user, increasing the complexity of creating CFD cases, but also allowing for lower computational cost by only increasing mesh sensitivity in areas where it may be needed, not throughout. Mesh can be of many different shapes and sizes, such as triangular prisms to tetrahedrals, with minimum edge sizes of cells, number of cells in an area, and localized sizing available to be defined by the user. For simplistic systems that allow it, mesh can be swept over a region to generate a structured mesh. Structured meshes allow uniformity across the mesh, but cannot adequately define irregularities in the geometry of choice. Utilizing unstructured meshes allows for finer control in irregularities, but lack the uniformity to make adequate profiles without high mesh count. If higher sensitivity in certain areas is required (wall, impeller, etc.) inflation layers add layers of progressively 
smaller mesh cells to the chose face/edge. This allows higher resolution of boundary layers in the fluid.

Finally, the user must define the physical models of fluid flow that are to be solved. These models modify the governing equations being used, such as turbulence models, multiphase models, or others. Also, any other equations that must be calculated with the flow field such as the energy equations, reactions or mass transfer may be defined. Additionally, boundary conditions for the model must be defined along all boundaries, either interior boundaries such as separate zones of fluid interacting, or exterior boundary conditions such as the inlet, outlet, and wall conditions. Finally, the solution must be initialized, usually from some standard value either the user inputs or assumed values based upon boundary conditions. The initialization process gives the solving routine a starting point, usually inlet or outlet conditions, from which the rest of the fluid mechanics may be solved. After this, any multiphase regions and their volume fractions may be defined.

All CFD programs are required to solve some form of the continuity equation and momentum balance through some use of fundamental equations, such as Navier-Stokes (Fluent), Lattice-Boltzmann (DMT), or others. The rest of this paper will discuss ANSYS Fluent as the CFD software of choice. Governing equations for an isothermal, nonreacting system are found in Equations 15 and 16.

Continuity

$$
\frac{\partial \rho}{\partial t}+\nabla\left(\rho v_{i}\right)=S_{m}
$$


Momentum: $\quad \rho\left(\frac{\partial v}{\partial t}+v \times \nabla v\right)=-\nabla p+\nabla \times \tau+f_{g}$

Definition of $\tau$

$$
\tau=\mu\left(\nabla v+\nabla v^{T}\right)-\frac{2}{3}(\nabla \cdot v)
$$

These equations are integrated across the computational mesh, reducing these to a finite difference algebraic equation(Bhaskaran and Collins 2002). These algebraic expressions are given in Equation 18.

$$
\phi \sum_{i}\left(A_{i}-S_{p}\right)=\sum_{i}\left(A_{i} \phi+S_{c}\right)
$$

The summations found in Equation 18 are taken on opposite faces of the computational cell. $A_{i}$ is a combination of convective and diffusive fluxes of each transport variable (temperature, velocity, etc.), while $S_{p}$ and $S_{c}$ are linear components of the source term found in Equation 20.

$$
S_{\phi}=S_{p} \phi_{p}+S_{c}
$$

A power law differentiating scheme is utilized to calculate derivatives of the transport variable and interpolate values between computational mesh faces. The 
algebraic equations such as Equation 19 are solved using a semi-implicit iterative method. This method involves initial and boundary conditions being defined for the system, then iteratively calculating values for the other cells in the system. The iterative solver will continue until either the convergence criteria on residual values defined by the user is met or the maximum number of iterations defined by the user is met.

The iterative process has multiple steps in the calculation. First, the current pressure of each computational cell is used to solve the equations of motion for velocity information. Following this, a form of the continuity equation is checked with the velocity values of the cells. The solution to this equation will result in corrections to the pressure and velocity fields. Following this, any other equations defined such as transport of a species or energy are solved. Fluid properties will be updated in each cell following these solutions, and residuals calculated from the prior iteration. If these residuals are lower than convergence criteria, the solution is complete in a steady-state case or moves forward one timestep in a transient case.

Commonly, surface monitors are employed to ensure convergence or measure values on certain surfaces. These values may be mass or area weighted averages, integrals, or standard deviations of certain parameters, fluxes, forces, stresses, or flows. These are updated along with the solution mechanism and can be another check of convergence in the solution.

Additionally, contours of parameters may be viewed in the software, giving maps of velocity magnitude, pressure, and age, to name a few. An example of a contour plot may be found in Russ, where age contours of each phase were displayed for the outlet of the pipeline section (Russ and Berson 2016). Histograms of data on surface may be made 
where the percentage of cells that report a value are grouped together to view distributions along surfaces.

\section{E. Volume Discretization for CFD}

CFD solutions require discretization of the system into smaller subsets from which PDE's may be solved numerically. In any continuous flow domain, a vector quantity such as velocity may be expressed in a scaled form

$$
v=v(x), 0<x<1
$$

The continuous domain utilized in Equation 21 has endpoints of $\mathrm{x}=0,1$, and PDE's are solved analytically using boundary conditions at each boundary. These solutions, while accurate from use of first principles equations, are increasingly difficult without assumptions in the system. However, discretizing the flow region, such as Figure 4, allows for the same vector component to be redefined as is in Equation 22.

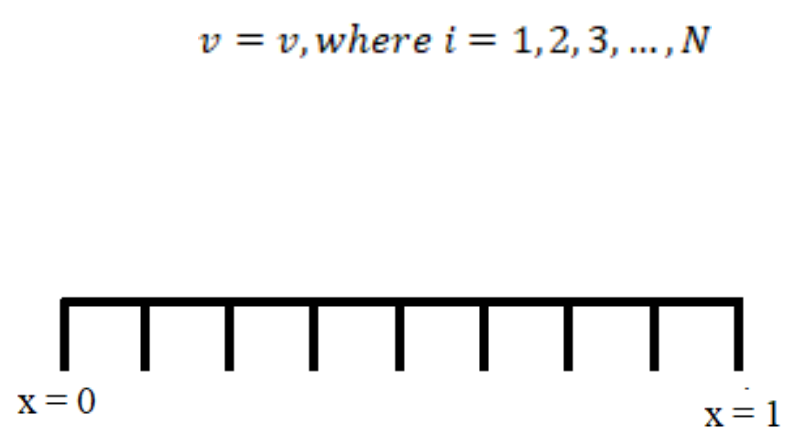




\section{FIGURE 4. DISCRETIZED DOMAIN FROM $0<\mathrm{X}<1$.}

Utilizing the discretized domain, finite difference methods may be used to convert PDE's into algebraic expressions. An example of a utilization of the finite difference method is given(Bhaskaran and Collins 2002).

For a given one dimensional PDE linear with $\mathrm{m}=1$ and nonlinear with $\mathrm{m}=2$,

$$
\frac{\partial v}{\partial x}+v^{m}=0,0<x<1, v(0)=1
$$

Assuming the grid points in Figure 4 of exact same distance from one another, Equation 24 may be rewritten into the form:

$$
\left(\frac{\partial v}{\partial x}\right)_{i}+\left(v^{m}\right)_{i}=0
$$

To compute the differential term, a Taylor's series expansion may be utilized in the form of Equation 25.

$$
v_{i-1}=v_{i}-\Delta x\left(\frac{\partial v}{\partial x}\right)_{i}+O\left(x^{2}\right)
$$


where $\mathrm{O}\left(x^{2}\right)$ is the truncation error past two terms of the expansion. Substituting this expression for $v_{i}$ in Equation 24 and assuming the truncation error negligible,

$$
\frac{v_{i}-v_{i-1}}{\Delta x}+v_{i}=0
$$

Equation 26 shows the result of the conversion of the original PDE into a linear, algebraic expression. Utilization of methods of such as these, while containing error terms, vastly reduces complexity for computation. For ANSYS Fluent, the finite volume method is used.

The finite volume method discretizes the domain into a quadrilateral grid with each point of the grid representing a node, or the center of a volume element. These elements are often triangular in two dimensional systems, while three dimensional systems often have a tetrahedral or hexahedral shape. In each cell, integral forms of the equations of conservation are solved using the faces of the cell as boundary conditions for the node. The ANSYS Fluent software package utilizes this finite difference method.

\section{F. Passive Scalars in CFD}

A passive scalar is a scalar value in the fluid which does not affect fluid flow such velocity or pressure. Equations based upon these scalars, either user defined or predefined, are usually calculated following the completion of the solving of the flow field. Examples of the use of passive scalars in CFD include mean age and mixture fractions in Wang et al.(2015). 
Mean age takes on the form of a non-diffusing passive scalar, with contours of physical mean age being contour plots of the concentrations profiles of the passive scalar of age. Since the scalar has no diffusive component (age cannot diffuse from one molecule to another), the fluid carries the scalar along the flow. Due to the discretization of the system into small volume elements, the age of the element becomes the average scalar concentration found in each infinitesimal volume of liquid contained in the cell. 


\section{EXPERIMENTAL}

\section{A. Experimental Workplan}

First, a reactor system with existing experimental RTD data (Zhang et al 1990) was selected to be used to validate the model. Validation was performed quantitatively by comparing the published number of tanks-in-series $(\mathrm{N})$ data and qualitatively by comparing RTD shapes with CFD derived N values RTD's.

Following model validation, RTD's were analyzed to create an array of cases with a range of $\mathrm{N}$. A range of $\mathrm{N}$ values were set by changing inlet flow rate and impeller speed. Flow rates were varied from $0.0078375 \mathrm{~kg} \mathrm{~s}^{-1}$ to $0.09405 \mathrm{~kg} \mathrm{~s}^{-1}$. Impeller speeds were varied between 0 and $90 \mathrm{rpm}$. Eight cases were established that gave $\mathrm{N}$ values equal to: $3.1,5.0,6.5,8.9,13.3,15.0,17.7$, and 18.9 .

Mean age was calculated using the transport of a user defined scalar (UDS). Mean age distributions were developed from the value of mean age at each mesh node in the plane of interest. The mean age at each node is the average age of all material passing through that location. Frequency of node values were plotted against dimensionless time. 
Both RTD's and mean age distributions were normalized by setting the area under the curves equal to one in order to compare curves. Mean residence time and average mean age of the outlet were each calculated and compared against one another for each $\mathrm{N}$ value. Additionally, RTD's and outlet mean age curves were compared for each $\mathrm{N}$ value. Contours of age across the outlet and along the length of the tubular reactor were extracted from the results.

Three cross sectional planes were added in the reactor for measurement of interior RTD's and mean age; the first plane above the second impeller, the second above the sixth impeller, and the third above the final impeller. RTD's and planar mean age curves were measured in the same manner as the outlet. Planar mean age curves and RTD's were compared similar to the outlet curves.

\section{B. Materials - Software and Hardware}

Geometries were constructed with ANSYS Design Modeler in Workbench 16.1 and 16.2. Computational mesh grids were created using Ansys ICEM. Flow simulations were run using Ansys Fluent 16. CFD Simulations were performed using the custom Phineas supercluster at the University of Louisville. Cases were run in parallel utilizing 18 cores. The Phineas supercluster included 9 nodes with 20 cores each, yielding an aggregate speed of 4.2 teraflops, combined memory of $128 \mathrm{~GB}$, and $70 \mathrm{~TB}$ total storage between local and remote storage. 


\section{CFD Simulations}

\section{Defining the Geometric Volume}

The same geometry was used for both model validation and the main work to compare mean age and residence time distributions. This geometric model mimics the reactor used in the experimental work of Zhang et al. (1990), where residence time distributions were measured in a tubular vessel with ten Rushton impellers. (Figure 5).

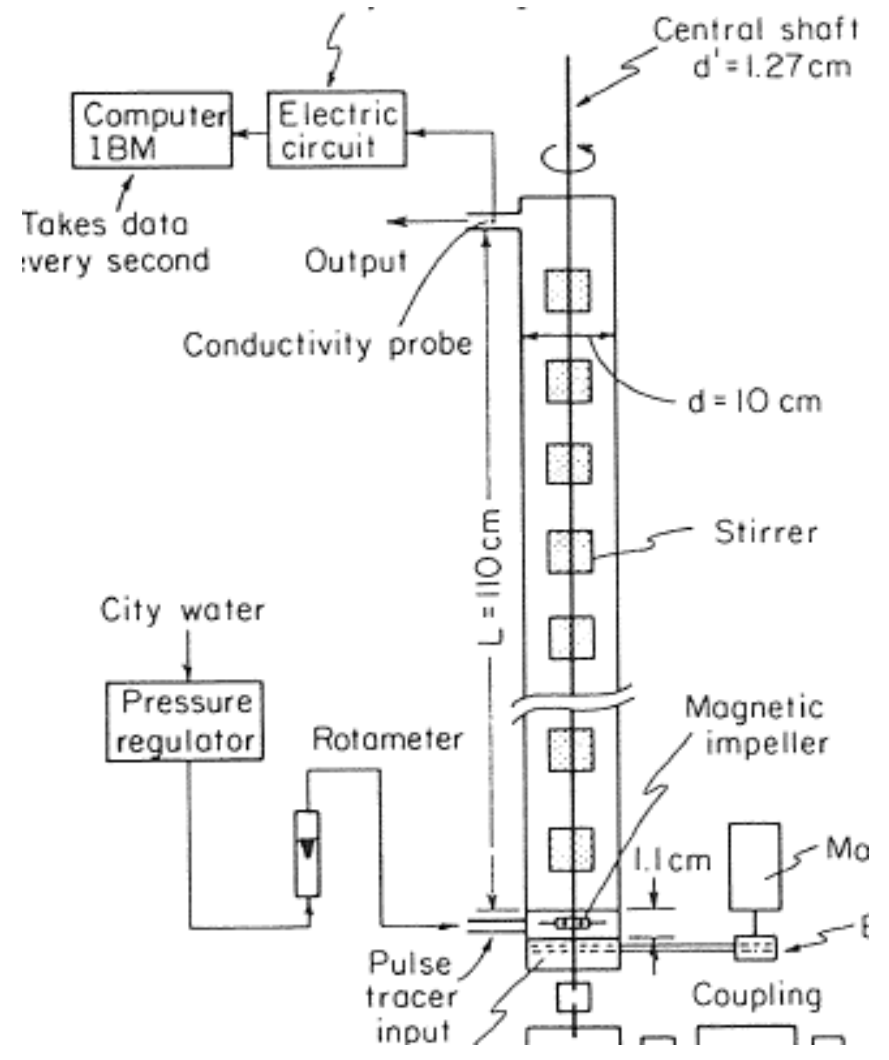

FIGURE 5. EXPERIMENTAL SCHEMATIC FOR ZHANG ET AL (1990).

Prior to geometric construction of the vessel, multiple assumptions on the physical vessel were required. First, Figure 5 shows the injection point of the tracer 
chemical as being in a smaller inlet pipe before entering the larger main section of the pipe. While the diameter of this section of pipe was known, the length from point of injection was not given. Additionally, Figure 5 shows that the conductivity probe to measure the concentration of the tracer compound was located outside of the tubular vessel, once again of an unknown length. For purposes of this study, a length of 5 centimeters was assumed based on relative scaling for both with the understanding that some levels of inaccuracy in the validation of the model will be due to these assumptions. Additionally, due to the lack of dimensions and the relative small section of the premixing section (volume encompassing the magnetic impeller), the rotation from the magnetic impeller was ignored.

There are further assumptions regarding the impeller and drive shaft. Due to the nature of constructing rotating parts in Ansys, the drive shaft was ignored in areas where the impellers were absent. Inclusion of the shaft throughout the volume of the tubular section caused instability and divergence in the resulting CFD simulation. Also, the number of impellers was not specified by Zhang. Based on the size of the impellers, distance between them, and the available space given the volume of the premixing section and the entire tubular vessel, a total possible number of impellers is 11 if placed exactly at the tightest configuration, or ten stirrers with vacancy above the outlet pipe. Due to the simplicity and the lack of a need for a stirrer above the outlet, it was assumed ten impellers was the correct number. Also, the shape of the stirrers was assumed to be perfect rectangular prisms without contouring to the edge, as the source reference did not specify. 


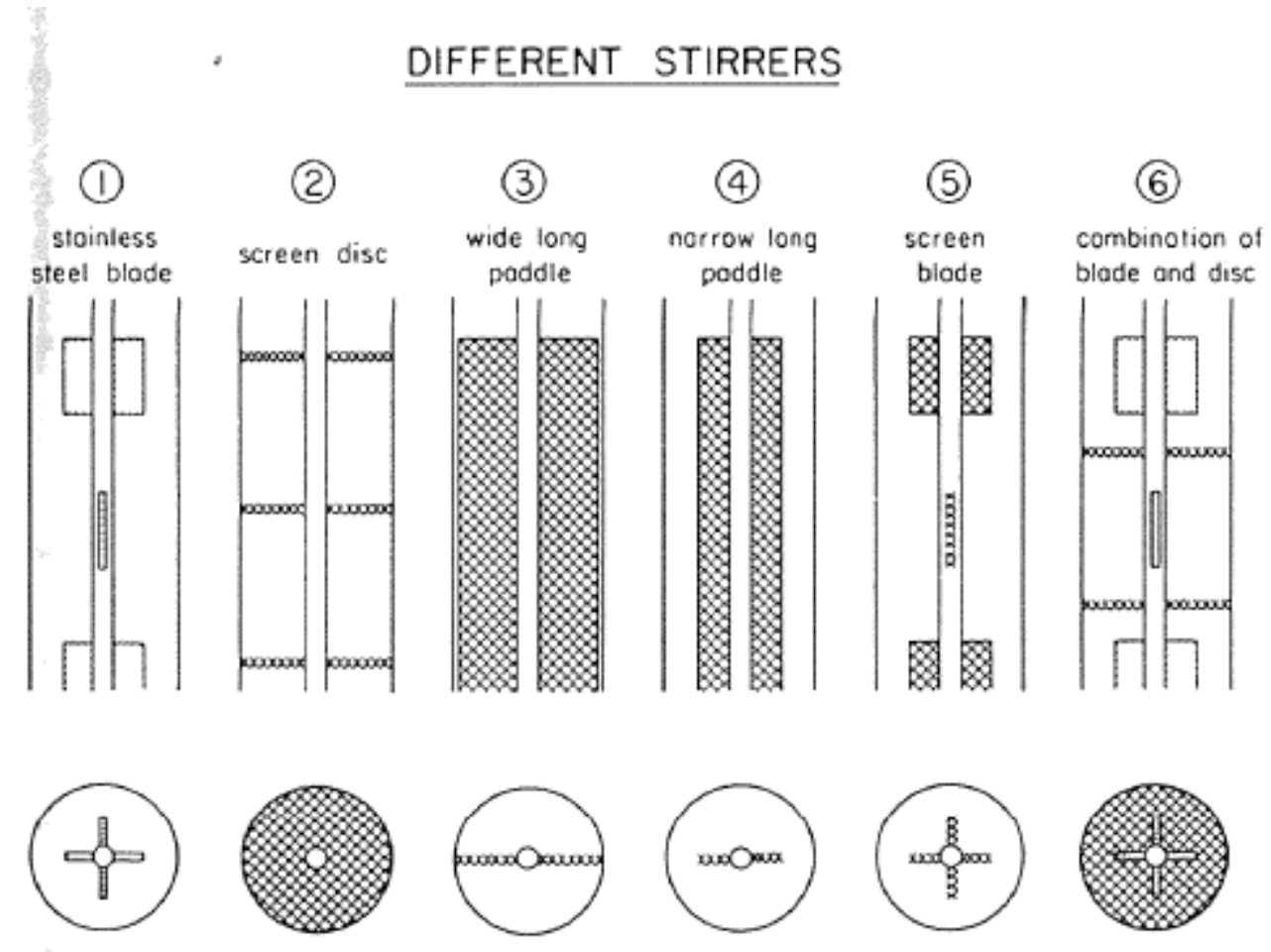

FIGURE 6. TYPES OF STIRRERS USED IN ZHANG ET AL (1990).

TABLE I

DIMENSIONS OF STIRRERS USED IN ZHANG ET AL (1990)

\begin{tabular}{|c|c|c|c|c|c|c|}
\hline No. & 1 & 2 & 3 & 4 & 5 & 6 \\
\hline Type & $\begin{array}{l}\text { Flat } \\
\text { blade }\end{array}$ & $\begin{array}{l}\text { Screen } \\
\text { disc }\end{array}$ & $\begin{array}{l}\text { Wide } \\
\text { long } \\
\text { paddle }\end{array}$ & $\begin{array}{l}\text { Narrow } \\
\text { long } \\
\text { paddle }\end{array}$ & $\begin{array}{l}\text { Screen } \\
\text { blade }\end{array}$ & $\begin{array}{l}\text { Combination } \\
\text { of stirrers } \\
1 \text { and } 2\end{array}$ \\
\hline Specification & $\begin{array}{l}2^{\prime \prime} \times 2^{\prime \prime} \\
0.025^{\prime \prime} \text { thick }\end{array}$ & $\begin{array}{l}3.9^{\prime \prime} \text { diameter } \\
4 \text { mesh }\end{array}$ & $\begin{array}{l}3.9^{\prime \prime} \text { wide } \\
38^{\prime \prime} \text { long } \\
8 \text { mesh }\end{array}$ & $\begin{array}{l}2^{\prime \prime} \text { wide } \\
38^{\prime \prime} \text { long } \\
8 \text { mesh }\end{array}$ & $\begin{array}{l}2^{\prime \prime} \times 2^{\prime \prime} \\
8 \mathrm{mesh}\end{array}$ & $\begin{array}{l}2^{\prime \prime} \times 2^{\prime \prime} \text { blade } \\
3.9^{\prime \prime} \text { diameter } \\
4 \text { mesh }\end{array}$ \\
\hline Spacing & $2^{\prime \prime}$ & $4^{\prime \prime}$ & - & - & $2^{\prime \prime}$ & $1^{\prime \prime}$ \\
\hline
\end{tabular}

*All stirrers are mounted on $\frac{5}{8} "$ o.d. sleeves which fit onto the central shaft. 


\section{Geometry Construction}

Geometric construction of the model was performed with ANSYS Design Modeler software in the ANSYS Workbench software package. The system geometry appears in Figure 5 and all required assumptions have been previously stated. During construction of the outside shell of the reactor, sketches were made according to the information provided and extruded. The distance between the top of the outlet pipe and the top of the main reactor section was chosen to be $5 \mathrm{~cm}$. To prevent sections of the inlet and outlet pipe being detached from the main section, an overlap of $0.5 \mathrm{~mm}$ was used. The impellers were drawn equidistant from the top of the main section to the top edge of the premixing section (see Figure 5). The shaft was constructed using a primitive (cylinder) with height of 0.96 meters (from $0.07 \mathrm{~m}$ to $1.03 \mathrm{~m}$ ) and radius given. The impellers were placed uniformly according to Impeller 1 in Figure 6 and placed evenly between the top of the premixing section and the bottom of the outlet pipe. After construction of the outside shell of the reactor and the sketch of the impeller was complete, the impeller was extruded by adding a frozen element inside of the reactor, which allowed for a separate entity to be created in overlapping space (tubular cylinder currently occupying the space of the impeller). Following this, a Boolean was used to subtract the impeller and shaft from the larger section of the fluid area.

When utilizing Fluent, rotating zones must be defined as volumes around the rotating object. Because of this, a cylinder was sliced from the volume of the main section surrounding the impeller with radius of $3 \mathrm{~cm}$ and height extending along the length of the shaft. 
Named selections for Fluent case development and meshing included

- Inlet (Face)

- Outlet (Face)

- Rotating Section (Volume)

- Main Section (Volume)

- Impeller (Faces)

- Tracer Injection (Volume)

The final geometric design appears in Figure 7.

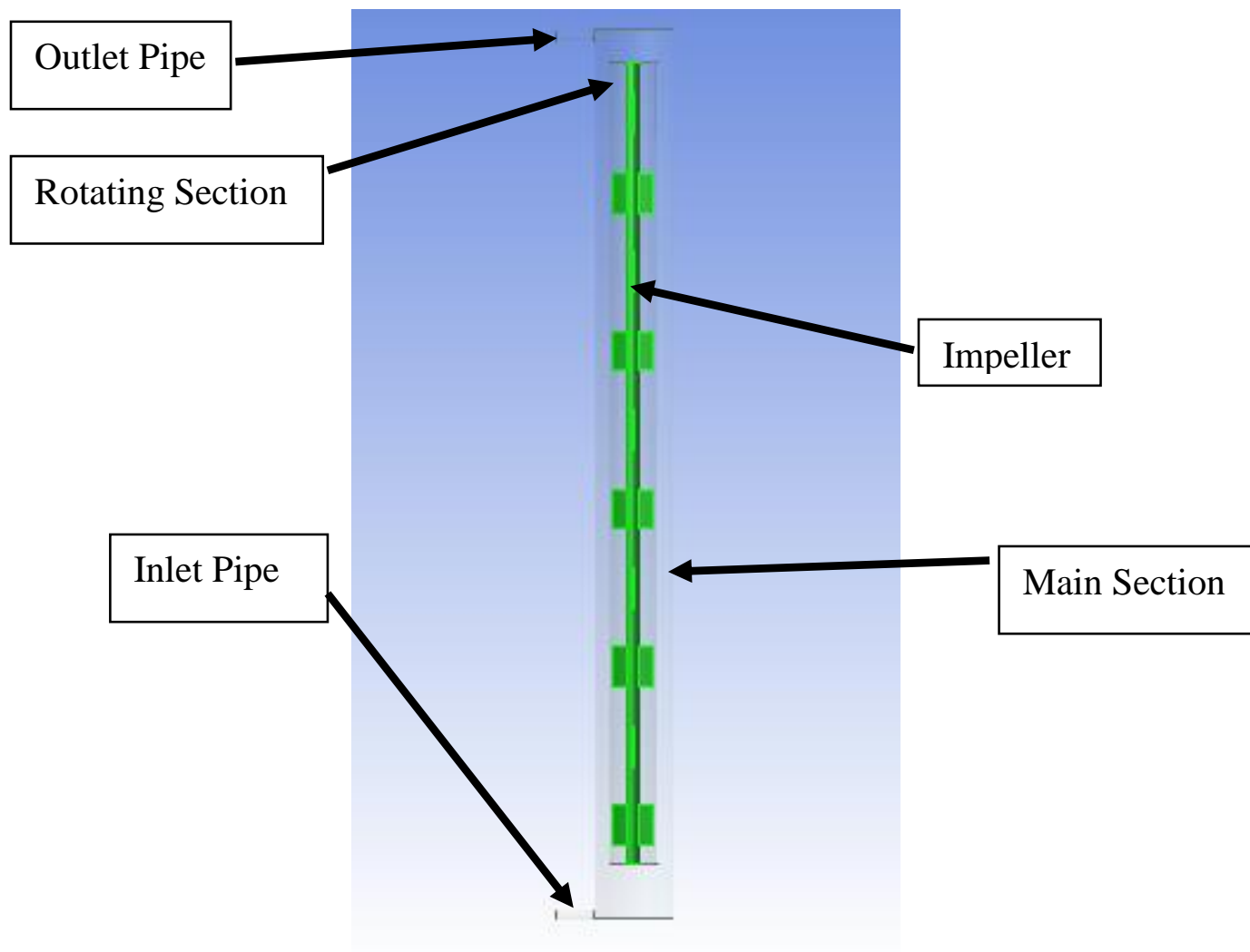

FIGURE 7. GEOMETRIC MODEL OF SYSTEM. TRACER INJECTION OCCURRED AT THE ENTRANCE OF THE INLET PIPE. 


\section{Meshing Setup}

Following the named selections of the geometric development, the program was closed to update the Workbench ${ }^{\mathrm{TM}}$ project file. Following this, the system was meshed using ANSYS Meshing ${ }^{\mathrm{TM}}$. The program was opened from the ANSYS Workbench ${ }^{\mathrm{TM}}$ interface and downstream of the geometry defined earlier.

Due to the small features of the impeller blades, a mesh could not be generated with the sweeping function. For this, increased global meshing, inflation around key features, and body sizing was used. The global mesh sizing was set on Fine Curvature, with a relatively high growth rate for the mesh. Additionally, global inflation was increased to improve sensitivity around walls.

Areas that required higher resolution meshing than provided by the global setting included the main section, rotating section, and the areas surrounding the impeller. Body sizing was conducted along the main and rotating sections to reduce the maximum element size to $0.00045 \mathrm{~m}$ in the main nonrotating section of fluid, and $0.00035 \mathrm{~m}$ for the inlet and outlet pipe, and the rotating section. Inflation was applied to the walls of the impeller to provide adequate sensitivity. This meshing method was adequate for the RTD's, but mean age curves required higher mesh at the outlet of the system to properly describe the spatial distribution of age, requiring a body sizing of $0.0003 \mathrm{~m}$ to be conducted along this section with higher inflation growth rates (1.7). Increased outlet mesh count was found to have little impact on the distribution. 
A mesh sensitivity analysis was conducted on the system using between 300,000 and 950,000 cells utilizing pressure along the interior wall of the main tubular section and the outlet as the metric for analysis.

TABLE II

MESH SENSITIVITY ANALYSIS VALUES

\begin{tabular}{|l|l|l|l|}
\hline Pressure $(\mathrm{Pa})$ & 300,000 & 650,000 & 950,000 \\
\hline Outlet & 595 & 421 & 393 \\
\hline Interior Wall & 129 & 60.3 & 57.9 \\
\hline
\end{tabular}

The mesh with 950,000 cells was chosen for the system due to the change in mesh sensitivity parameters below $5 \%$. When mean age calculations were performed, narrow distributions at the outlet may have been a result of low mesh count of just 52 cells in the outlet plane. Mean age distributions plot frequency of age (mean age in each cell) vs. age, so the number of cells may affect the frequency distribution. The mesh count was increased for the revised mean age calculations to $1,500,000$ cells, with the additional cells being added in the inlet and outlet pipes. This increased the outlet mesh to a total of 92 cells.

\section{Case Setup}

The meshing editor was closed, allowing the Workbench ${ }^{\mathrm{TM}}$ project to update. Following this, a Fluent module was placed downstream of the mesh, allowing for 
importation of the current geometry and mesh into Fluent. Mesh quality was checked at the start of the simulation with the minimum orthogonality verified to be $>0.01$. If it was not, a Smooth/Swap operation was performed to correct the mesh quality.

As shown in Zhang et al (1990), the flow through the main section remains in the laminar flow region throughout most of the inlet velocity and impeller rpm range used for measurements, only moving to transitional flow for the highest flows and rpms. Reynolds numbers defined using the typical pipe flow definition range from $100-1600$ (which is below the 2100 threshold for laminar flow) for the main flow section. Stirrer Reynolds numbers varied from 1080 to 4321 , which is at the low end of the transition range. To confirm it was acceptable to use the laminar model for this range, two cases were tested with a turbulence model. RTD and mean residence time remained within $3 \%$. At the highest space velocity $\left(1.6 \mathrm{~cm} \mathrm{~s}^{-1}\right)$, transitional flow begins in the inlet and outlet pipes due to the significantly lower diameter, moving likely into the turbulent domain of Reynolds numbers. This case was found to have instability while using the same model setup (laminar) used for the other cases. Because of this, subsequent cases were set up at lower flow rates. Additionally, at the highest rpm used transitional flow begins at the impeller tip. A case utilizing a turbulent model was performed for the highest impeller speed with less than $3 \%$ change in the measured RTD and no noticeable change in the flow field as compared to the laminar model used throughout this study. For RTD calculation, a multiphase model must be utilized. The tracer was defined as a phase with material properties equivalent to the primary phase (water). Average concentration of the tracer phase was determined across the outlet over time. The "mixture" model was utilized for this experiment, due to the simplicity, ability to use the outflow boundary 
condition, and the high volume-fraction cutoff $\left(10^{-15}\right)$. Phases were chosen by navigating to the phase menu (Multiphase -> Phases), then opening the air phase. Following this, liquid water was selected from the Fluent database, and Change/Create was clicked. While liquid water was still open, the name was changed to "tracer" and the chemical formula removed. Change/Create was clicked once more, opting to not overwrite liquid water. Phase 1 was selected as water; Phase 2 was selected as tracer. The other models available were left off or in default choices.

Zhang et al (1990) used space velocity and impeller rpm as the two primary variables of note throughout the study. Inlet boundary conditions were found by converting the space velocity into a mass flow rate. Inlet mass flow conditions for the secondary phase were defined to be zero. Due to the lack of outlet boundary conditions, an outflow boundary condition was used. Outflow boundary conditions were used at the outlet, which is defined by the Fluent user's guide (2016) as a boundary condition where zero diffusive flux occurs and overall mass balance correction from all inlets. Also, since velocity and pressure are both undefined in this case, they must be extrapolated from the interior of the system.

Impeller rotation was defined utilizing the separate cell zone (Rotating Section), with a frame motion of a defined angular velocity ( $\mathrm{rad} / \mathrm{s})$. RPM was converted to $\mathrm{rad} / \mathrm{s}$ for this value. The physical impeller itself, defined as a wall inside of the Rotating Section, was set to rotate at zero angular velocity relative to the surrounding cell zone.

When conducting RTD measurements, a certain amount of the secondary phase must be added to the inlet of the system. To accomplish this, the Tracer Injection cell zone, which was defined as one mesh layer thick at the inlet, was patched following 
initialization to $5 \%$ by volume tracer. This allowed a second named phase other than water with the same properties of water to be uniformly injected across the inlet instantaneously. To measure the RTD, a surface monitor of the mass-weighted average of the tracer concentration was recorded at the outlet of the system.

Mean age calculations did not require multiphase operation, but did require the use of a user-defined scalar (UDS) to compute mean age. This scalar was defined in all cell zones with a mass flow rate flux condition. Inlet diffusion was unchecked. The material's (water) UDS diffusivity was edited to a constant value of zero, implying that age does not diffuse from one fluid packet to another. The inlet UDS boundary was changed to a value of 0 , whereas the outlet and other walls were set to a flux of 0 . UDS source terms were added for each cell zone the fluid passed through (all of them) equivalent to the density of the fluid. This is due to Fluent's flux of UDS being mass flow rate based, not velocity based. Mean age was calculated using a steady-state solution. 


\section{RESULTS AND DISCUSSION}

\section{A. Model Validation}

Model validation was performed by comparing computationally derived RTD curves with RTD curves reported by Zhang et al(1990). Additionally, a more quantitative approach to model validation using the plot of $\mathrm{L} / \mathrm{Nd}$, defined by the length of the tubular reactor divided by the diameter of the vessel times N, was performed. Figure 8 shows the RTD curves generated in this work beside those generated by Zhang et al(1990). (The RTD for the $1.6 \mathrm{~cm} / \mathrm{s}$ space velocity case was not shown due to Fluent difficulty in convergence.) 

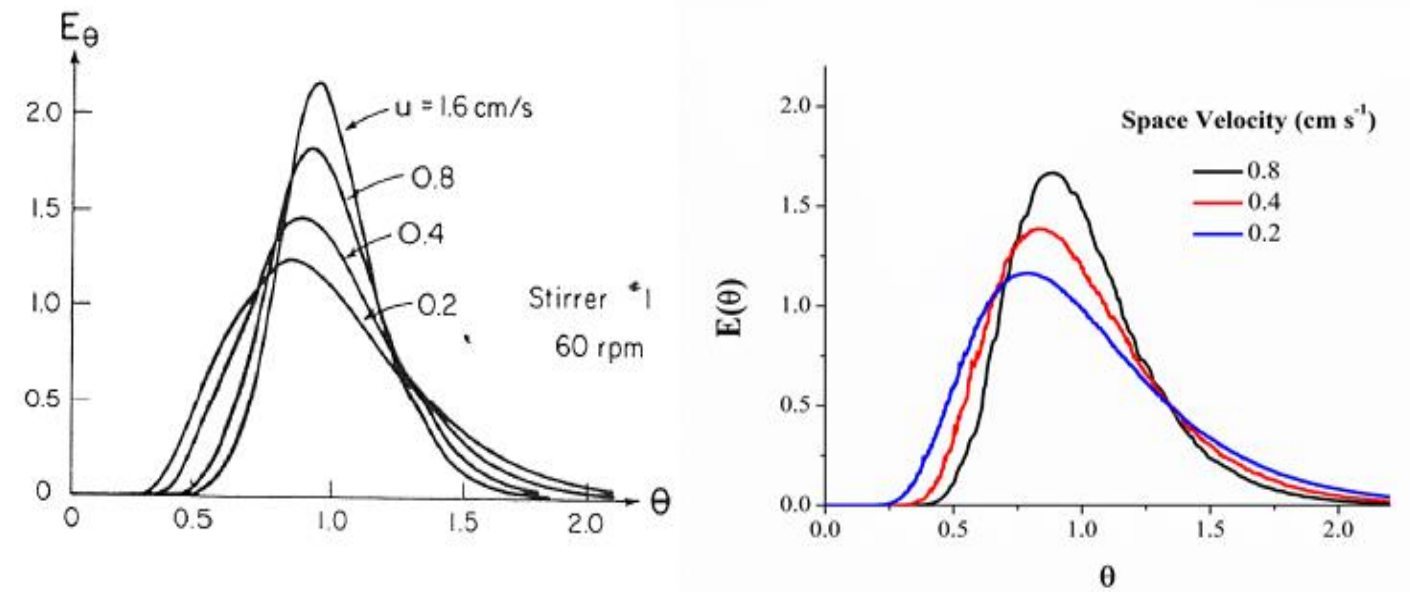

FIGURE 8. QUALITATIVE VALIDATION OF RTD’S. (Zhang et al. 1990)

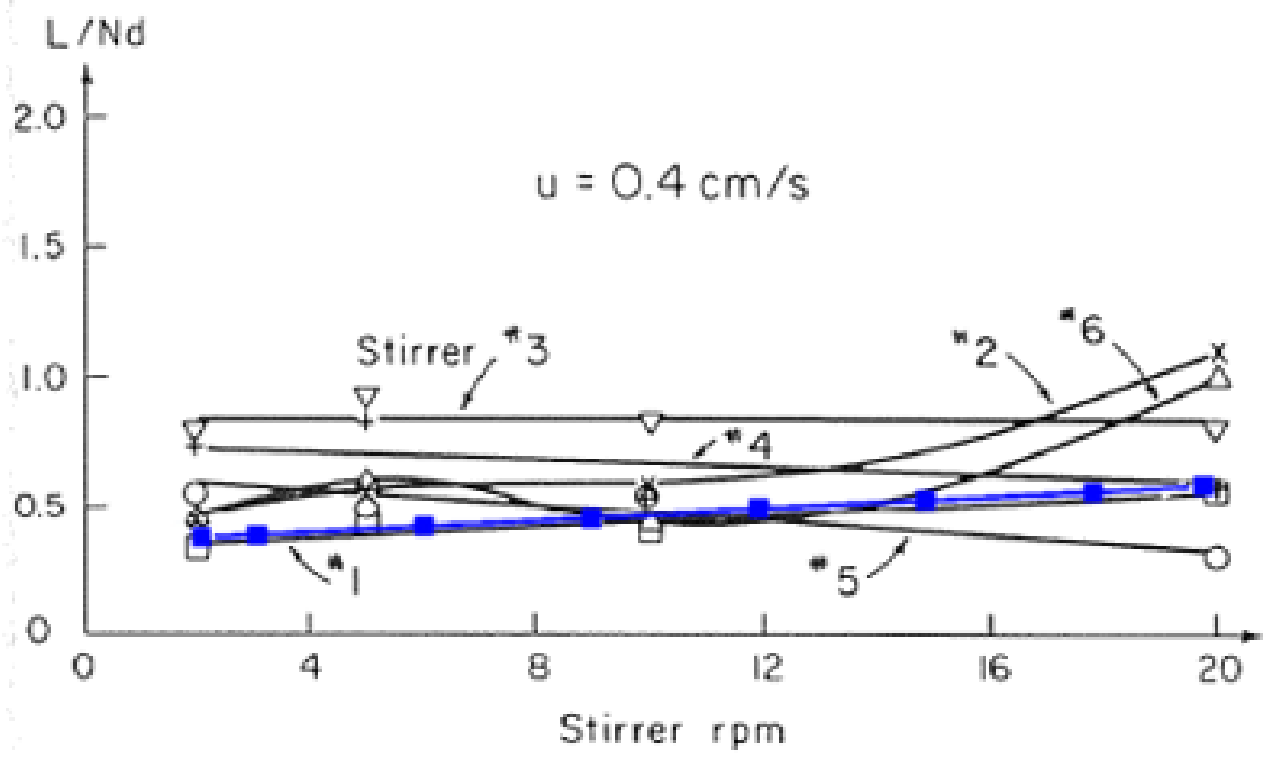

FIGURE 9. QUANTITATIVE VALIDATION OF MODEL AND RTD METHOD USING L/Nd. THE BLACK SQUARE LINE AND BLUE LINE CORRESPOND TO EXPERIMENTAL DATA AND CFD DATA, RESPECTIVELY. (Zhang et al. 1990)

$\mathrm{L} / \mathrm{Nd}$ was calculated through the geometry given in Figure $5(\mathrm{~L}=110 \mathrm{~cm}, \mathrm{~d}=10$ $\mathrm{cm})$. Based upon these figures, the flow model and RTD measurement technique was 
assumed to be valid. Computational L/Nd values were within $+/-3 \%$ of published experimental data.

B. RTD and Mean Age Measurements at Different Levels of Mixing

Following validation of the model, parameters of the system had to be changed to build the panel of cases for the use of characterizing mixing. These cases were developed by changing impeller rotation speed and mass flow rate. Goals of the experiment were to achieve the widest range of possible $\mathrm{N}$ values. Graphs of the RTD curves and a table of cases and the value of $\mathrm{N}$ are found in Figures 10 and Table III.
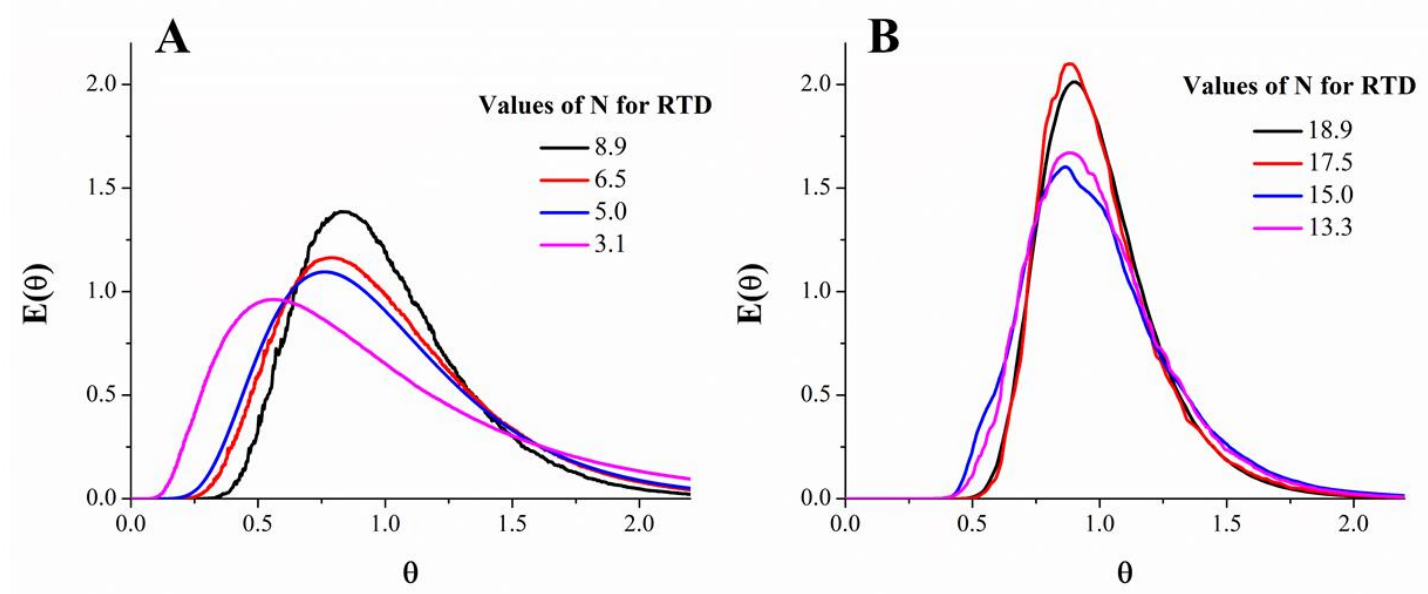

FIGURE 10. DIMENSIONLESS RTD CURVES OVER A RANGE OF MIXING QUANTIFIED BY THE TANKS-IN-SERIES MODEL FOR N BETWEEN (A) 3.1 AND 8.9, AND (B) 14.4 AND 18.9.

To develop the range of $\mathrm{N}$ used (3.1-18.9), multiple flow rates and impeller speeds were required. Within any given fixed flow rate, the variation of RPM could 
generate a maximum range of 5-6 $\mathrm{N}$ values. Setup parameters for the CFD cases used are found in Table 4.1. In addition, iterations required for the computation of mean age and RTD calculations varied considerably, noting the drastically reduced computational cost. Time per iteration was approximately equivalent for each case in both RTD and mean age computations. Iteration number for RTD curves increased with decreasing flow rate due to higher numbers of timesteps required for the tracer compound to exit.

TABLE III

CASE SETUPS FOR N DISTRIBUTION WITH COMPUTATIONAL ITERATIONS

\begin{tabular}{|c|c|c|c|c|}
\hline N-Values & Mass Flow Rate & Impeller Speed (rpm) & Iterations & Iterations \\
\hline 18.9 & 0.03135 & 18 & $($ RTD $)$ & (Mean Age) \\
\hline 17.5 & 0.0627 & 15 & 315,000 & 25,000 \\
\hline 15.0 & 0.09405 & 15 & 315,000 & 25,000 \\
\hline 13.3 & 0.0627 & 60 & 315,000 & 25,000 \\
\hline 8.9 & 0.03135 & 60 & 315,000 & 25,000 \\
\hline 6.5 & 0.015675 & 60 & 680,120 & 25,000 \\
\hline 5.0 & 0.0078375 & 60 & $1,925,000$ & 25,000 \\
\hline 3.1 & 0.0078375 & 90 & $1,925,000$ & 25,000 \\
\hline
\end{tabular}

As seen in Figure 10 the RTD curves tend to have taller peaks and narrower distributions for high N values, which agrees with Zhang et al. (1990) and Fogler (2006), This is intuitive, as high $\mathrm{N}$ values begin to approximate plug flow behavior. Additionally, 
as values of $N$ increase the peak position along the $x$-axis $(\Theta)$ shifts towards 1 . Since $\Theta$ is defined as the time divided by the mean time, a peak value of one corresponds to plug flow, where all the tracer leaves at the mean time.

Correlations between mean age and RTD curves were then examined (Figures 1118). Each plot was normalized. For normalized time, the definition of $\Theta$ was used (Equation 2). For normalized frequency, the area underneath the mean age curve was normalized to one, equivalent to the RTD curves.
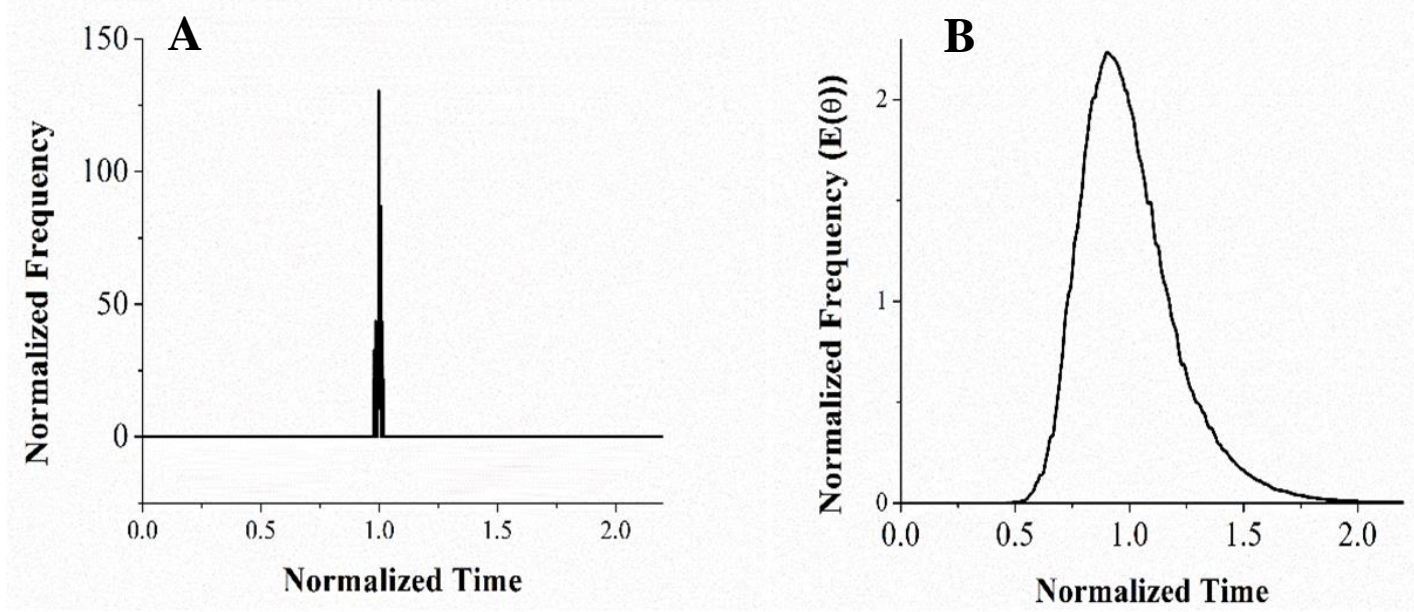

FIGURE 11. (A) OUTLET MEAN AGE FREQUENCY AND (B) RTD. $(\mathrm{N}=18.9)$. 

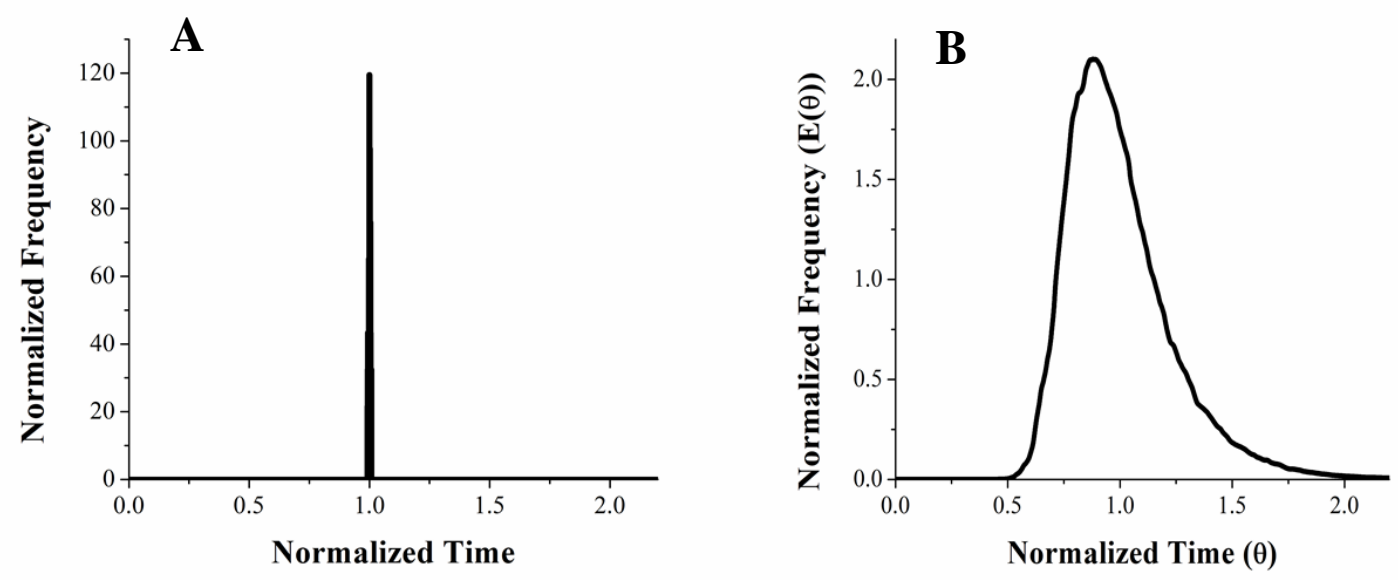

FIGURE 12. (A) OUTLET MEAN AGE FREQUENCY AND (B) RTD. (N = 17.5).
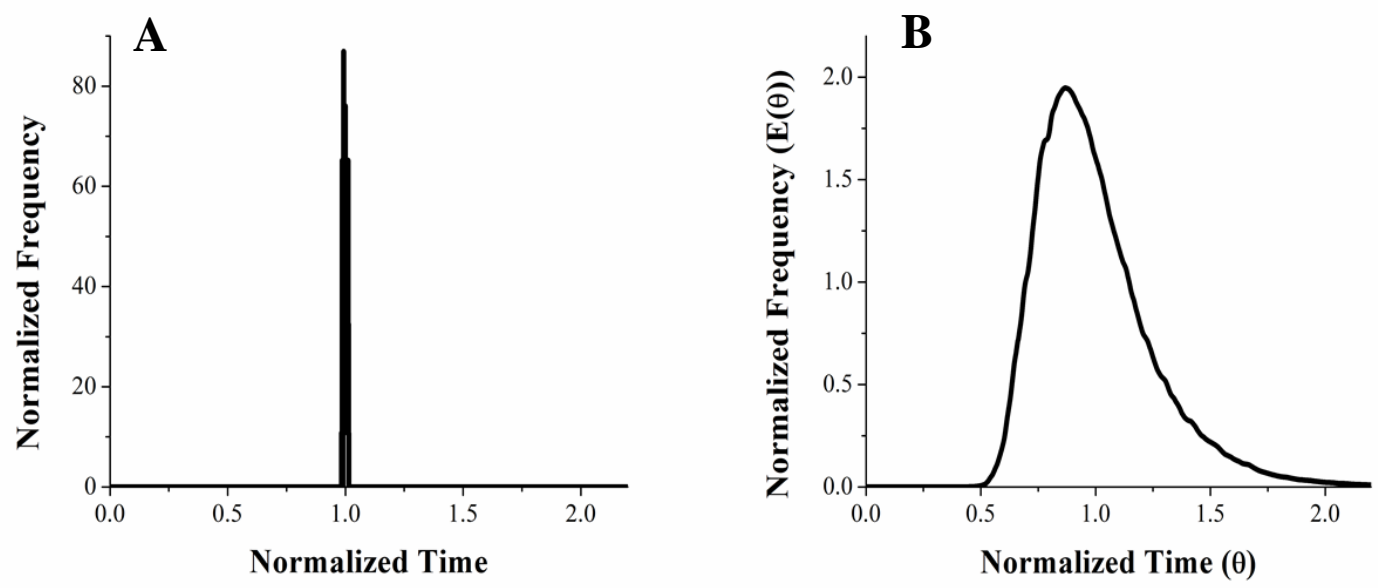

FIGURE 13. (A) OUTLET MEAN AGE FREQUENCY AND (B) RTD. ( $\mathrm{N}=15.0)$. 

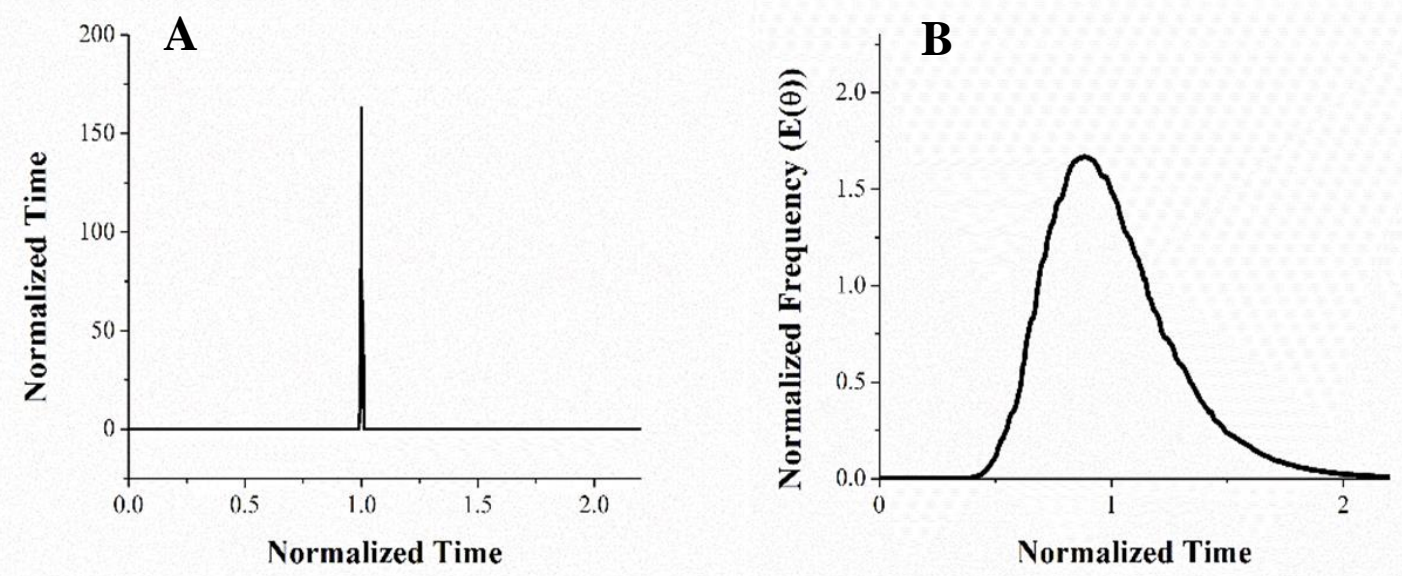

FIGURE 14. (A) OUTLET MEAN AGE FREQUENCY AND (B) RTD. (N = 13.3).
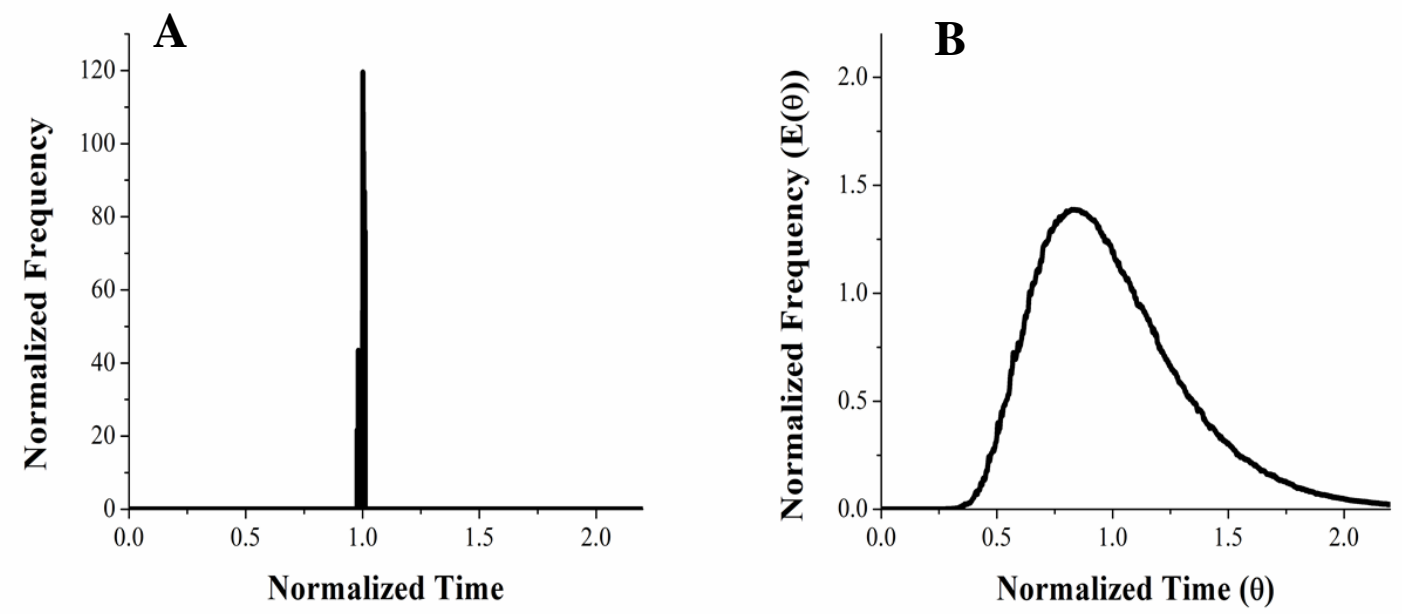

FIGURE 15. (A) OUTLET MEAN AGE FREQUENCY AND (B) RTD. ( $\mathrm{N}=8.9$ ). 

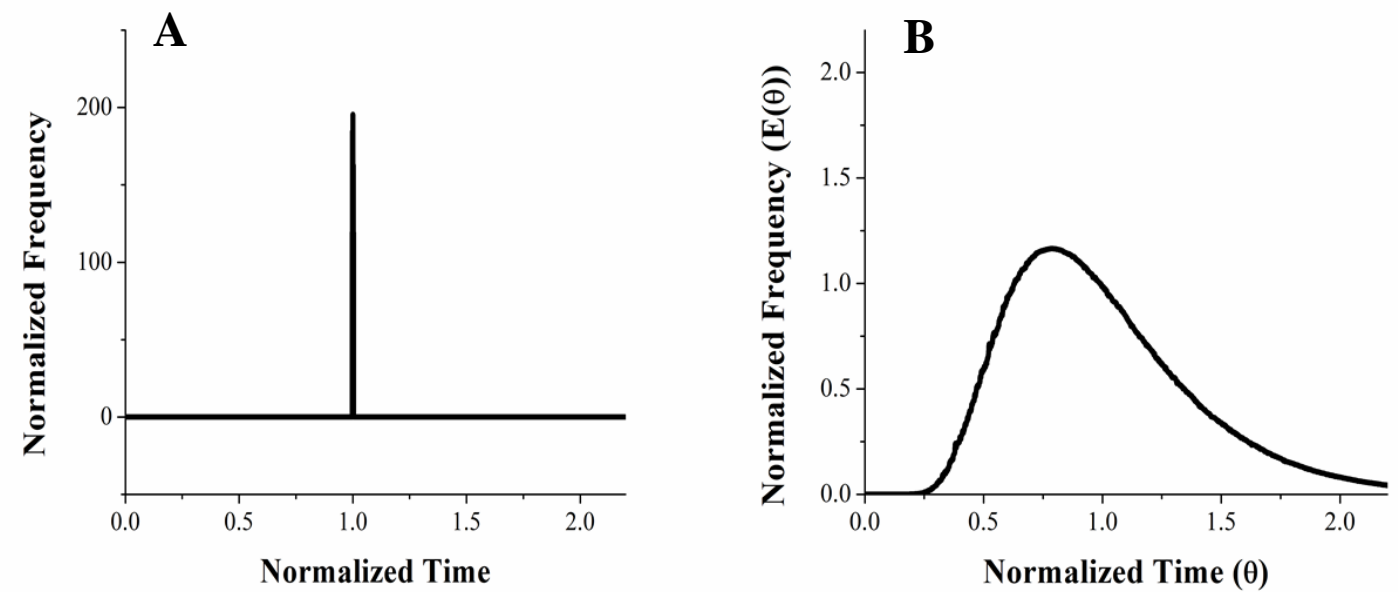

FIGURE 16. (A) OUTLET MEAN AGE FREQUENCY AND (B) RTD. ( $\mathrm{N}=6.5$ ).
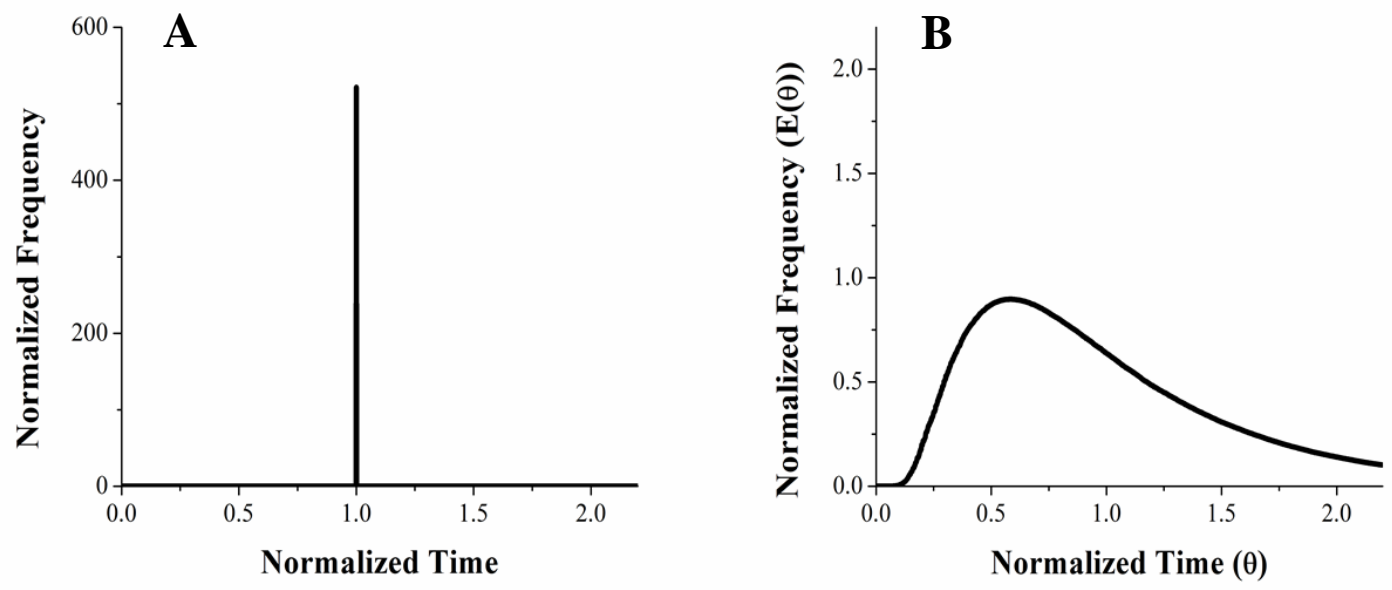

FIGURE 17. (A) OUTLET MEAN AGE FREQUENCY AND (B) RTD. (N = 5.0). 

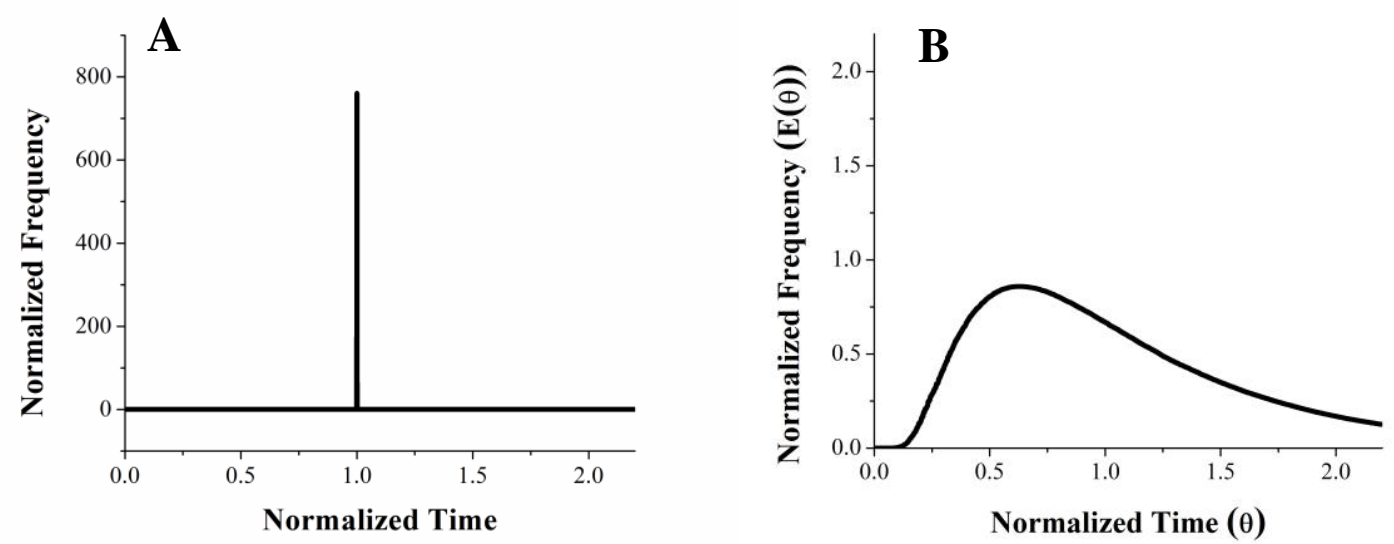

FIGURE 18. (A) OUTLET MEAN AGE FREQUENCY AND (B) RTD. ( $\mathrm{N}=3.1$ ).

TABLE IV

COMPARISON OF MEAN RESIDENCE TIME AND AVERAGE OUTLET MEAN

AGE

\begin{tabular}{|c|c|c|c|}
\hline N-Values & Mean Residence & Average Outlet & Difference (\%) \\
& Time (s) & Mean Age (s) & \\
\hline 18.9 & 300.7 & 279.5 & $7.05 \%$ \\
\hline 17.5 & 155.4 & 139.4 & $10.30 \%$ \\
\hline 15.0 & 101.4 & 93.7 & $3.59 \%$ \\
\hline 13.3 & 144.3 & 139.7 & $27.45 \%$ \\
\hline 8.9 & 385.8 & 279.9 & $26.35 \%$ \\
\hline 6.5 & 761.0 & 560.5 & $30.43 \%$ \\
\hline 5.0 & 1594.3 & 1109.1 & $24.19 \%$ \\
\hline 3.1 & 1477.7 & 1120.2 & \\
\hline
\end{tabular}




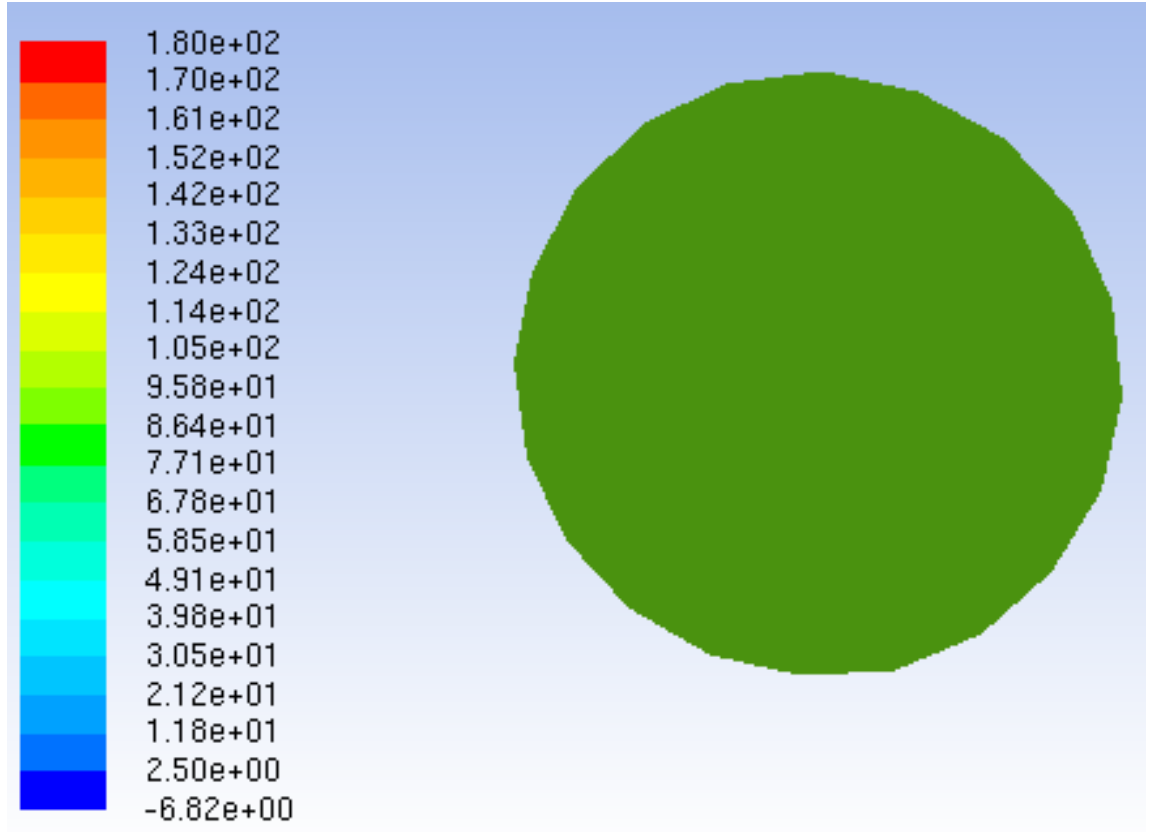

\section{FIGURE 19. CONTOUR OF MEAN AGE AT OUTLET OF SYSTEM.}

Mean age of the outlet comes as a very tight distribution around the mean, far more so than the RTD curves (Figure 19). Contours of age (Figures 21-22) along a vertical slice in the reactor show that at the entrance to the outlet pipe section, values of age aggregate towards the mean due to high mixing in the region. Further, due to the flow through the small outlet section being relatively fast, effectively plug flow, the age distribution remains narrow throughout the section of outlet pipe. Because of these phenomena, the variation between the mean age curve at the outlet over all cases for $\mathrm{N}$ studied here remains negligible. A sample contour of outlet age in Figure 19 demonstrates the narrow distribution. Liu and Tilton (2010) showed a similar trend in their Figure 3, where a large range of mean age exists throughout the domain, but the mean age becomes almost uniform at the exit. 
Also, a discrepancy from the mean residence time and the average mean age of the outlet may be observed. The fact that the average mean age is always lower than the mean residence time is noteworthy. A plausible reason for this behavior is found in how each measurement begins. With mean age measurements, the effective measuring agent is the fluid front. This front enters the system with a set velocity equal to inlet velocity. However, the RTD's are traditionally measured by a tracer injected perpendicular to the fluid front, causing the tracer to change directions and increase in velocity to match the fluid at the inlet. In this study, the tracer was not injected perpendicularly, but was added in such a way that it begins with no momentum in the direction of initial fluid flow. Because of this, the inlet fluid front will physically pass the tracer compound and have shorter exit times.

Additionally, the work of Holzer et al (2012) gives another plausible explanation. In their work involving mean age and mean residence time, they showed that the two can differ in cases where flow is not purely advective. Additionally, they showed that for these cases where diffusion becomes a factor in flow, the mean age will always be smaller in time than the mean residence time. Recirculating flow due to the rotating impellers can produce pockets of low velocity outside the primary recirculation zones where flow is more dispersive than convective, particularly in cases where the mixing from impellers becomes dominant to the overall flow field $(\mathrm{N}<10)$. This would yield a lower mean age relative to mean residence time according to Holzer et al (2012). A contour of the velocity magnitude shows areas of flow multiple magnitudes slower than the primary flow path (Figure 20). In these regions, diffusive flow can become a larger factor in the total flow profile. 


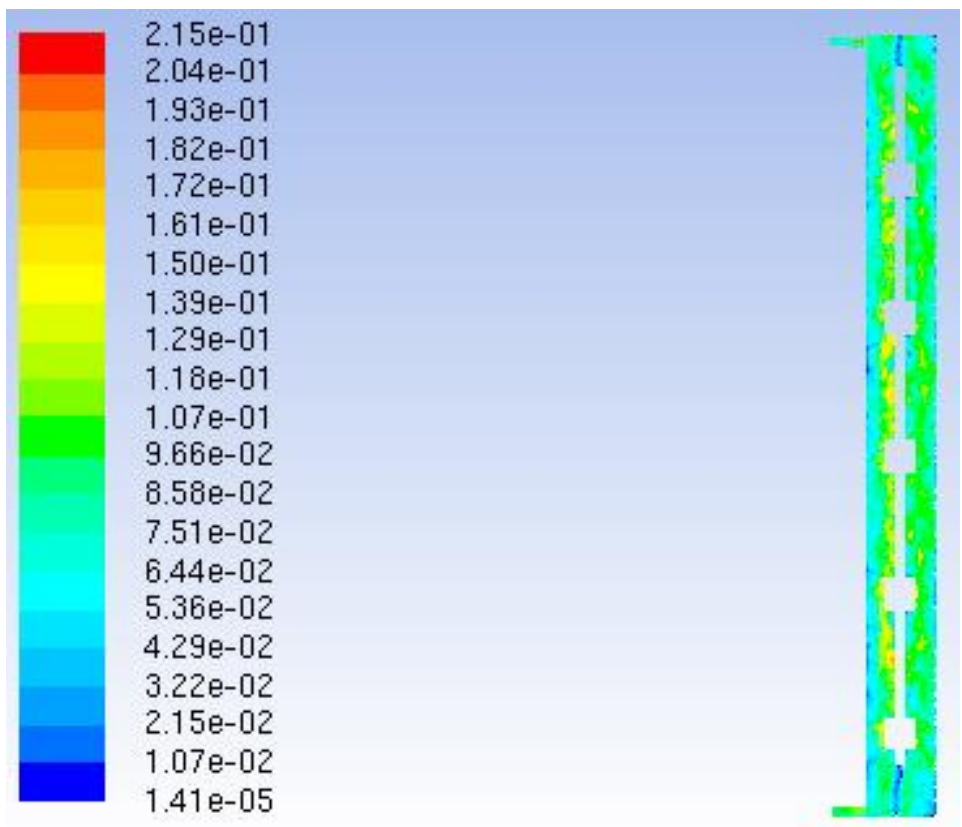

FIGURE 20. A CONTOUR OF VELOCITY MAGNITUDE ACROSS THE LENGTH OF THE VESSEL.
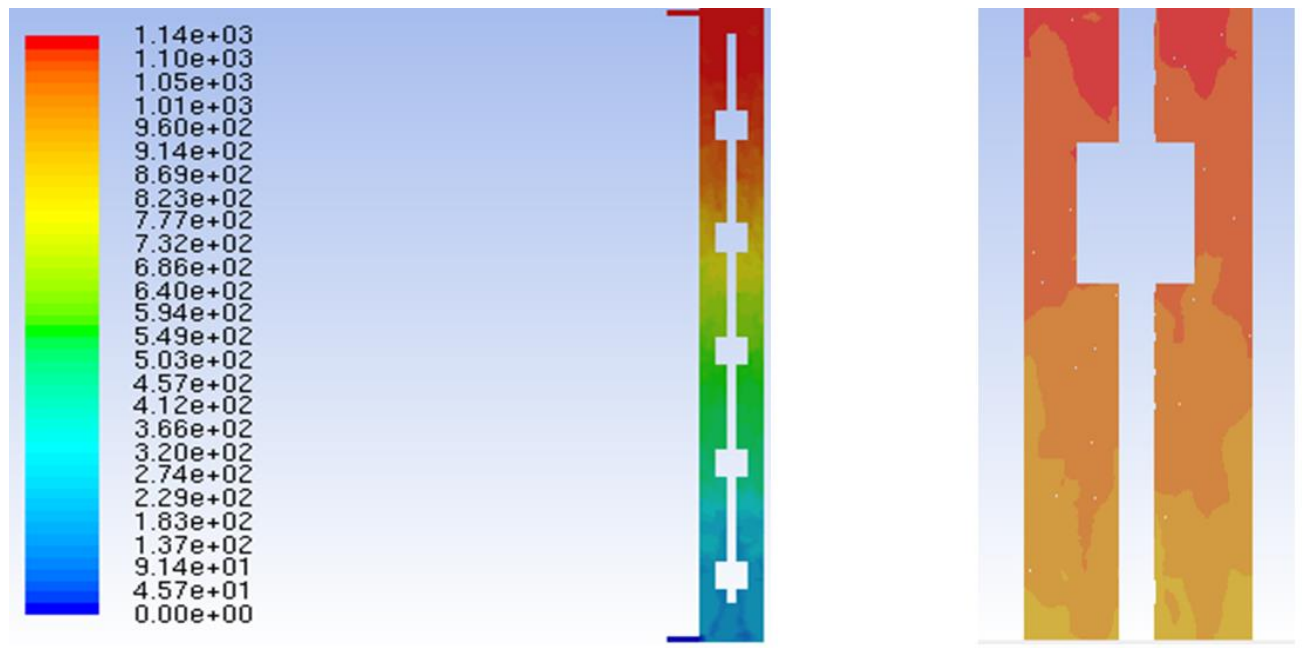

FIGURE 21. CONTOUR OF MEAN AGE ALONG THE LENGTH OF THE SYSTEM AT $\mathrm{N}=5$. 

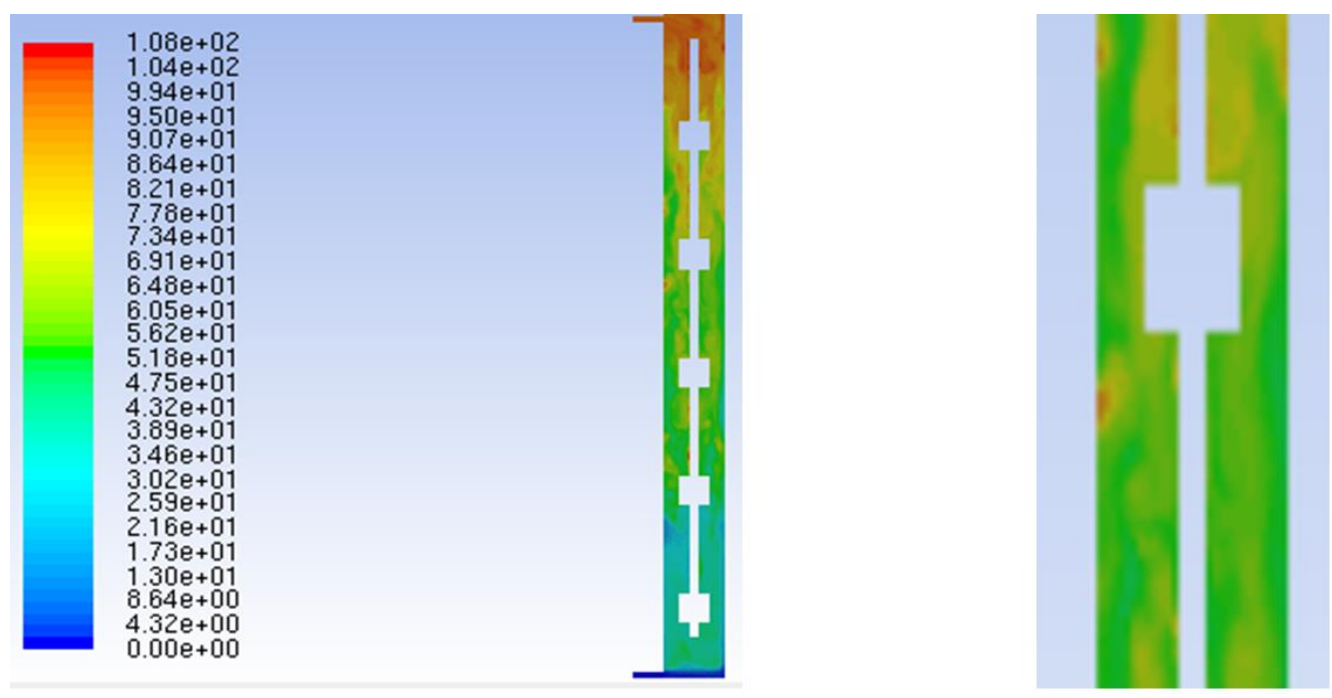

FIGURE 22. CONTOUR OF MEAN AGE ALONG THE LENGTH OF THE SYSTEM AT $\mathrm{N}=15.0$

Figures 21 and 22 show contours of mean age along the length of the reactor. In addition to the mean age distribution through ought the reactor, the figures also show differing patterns of mean age as the fluid front progresses through the reactor. The $\mathrm{N}=5$ contour shows relatively uniform transitions of mean age values, with age progressing as the fluid flows through the vessel. The $\mathrm{N}=18.9$ contour shows a much wider disparity of age in the fluid front with age generally with areas of localized higher and lower age. Since the flow rates differ (Table IV), a maximum mean age change of approximately a factor of 8 is expected.

A study into the distribution of mean age along the length of the reactor was conducted. Additionally, RTD's were determined along the length of the reactor. Local levels of mixing could be gathered from the RTD curves and compared to mean age, allowing a comparison to be made between the two methods without the aggregation towards the mean found at the outlet pipe. RTD's were determined at three cross- 
sectional planes: a lower plane above the bottom 2 impellers, a middle plane above the bottom 6 impellers, and a high plane above all impellers, but before the entrance to the outlet section of the pipe. Figure 23 shows the placement of these planes for comparison.

\section{Comparison of Interior RTD's and Mean Age Curves}

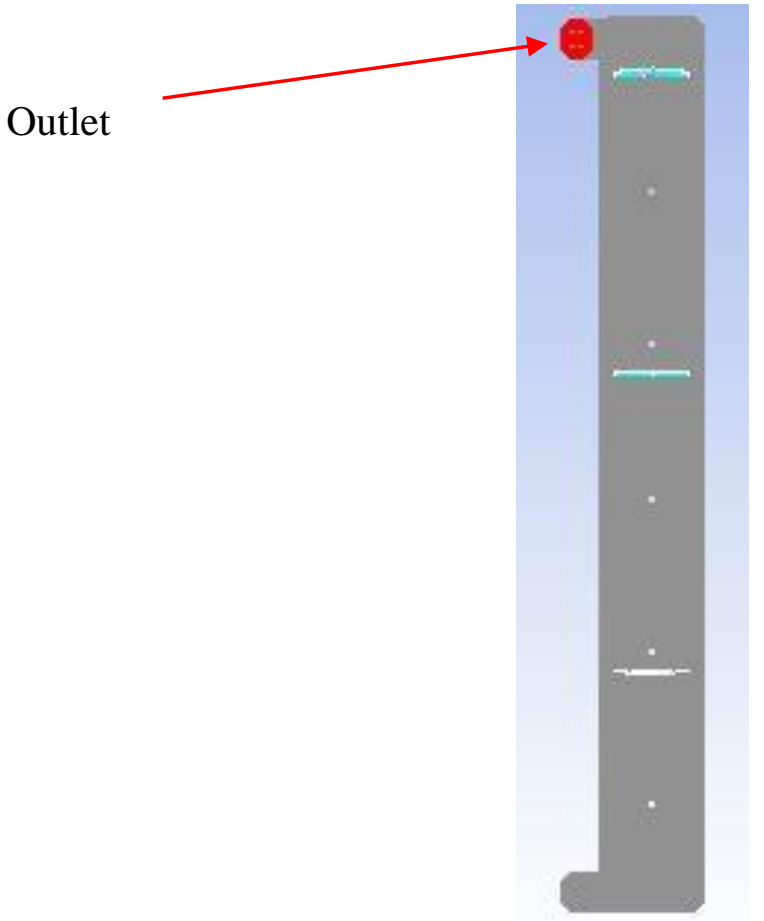

FIGURE 23. LOCATION OF INTERMEDIATE PLANE FOR RTD AND MEAN AGE MEASUREMENTS. OUTLET IS SHOWN AS A REFERENCE.

Utilizing the intermediate sections of a vessel for measurement of RTD's allowed for additional $\mathrm{N}$ values to be studied since $\mathrm{N}$ varied along the length of the reactor. Figures 24-31 show the intermediate RTD curves plotted alongside frequency plots of mean age. Figures 24-27 are of the $\mathrm{N}=5.0$ vessel (total vessel), whereas Figure 28-31 are of plots of the $\mathrm{N}=18.9$ vessel. 

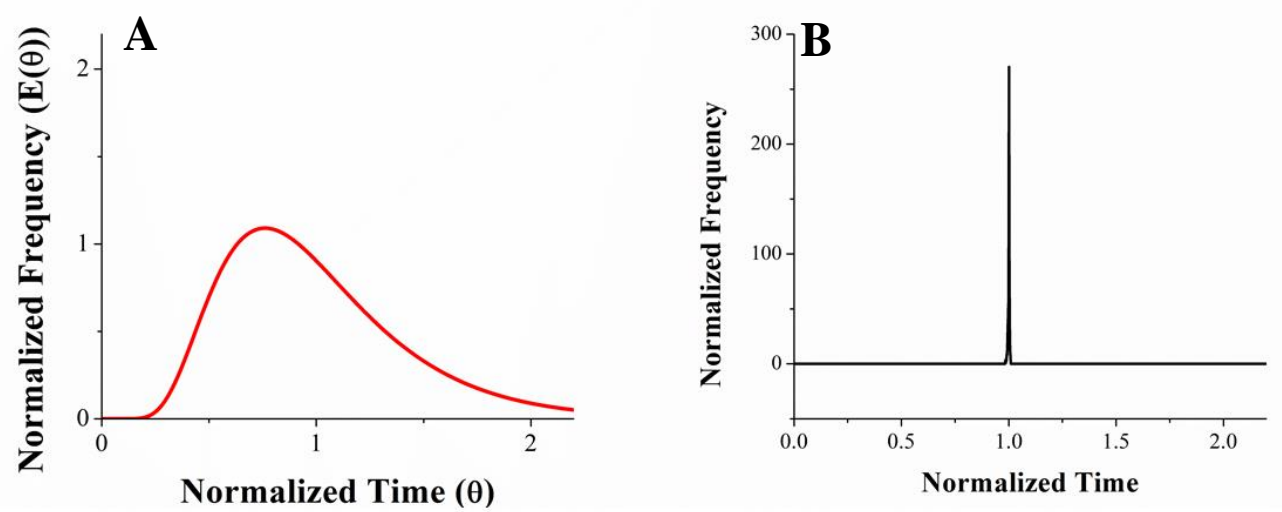

FIGURE 24. (A) RTD AND (B) MEAN AGE CURVE OF HIGHEST PLANE OF N=5.0 VESSEL.
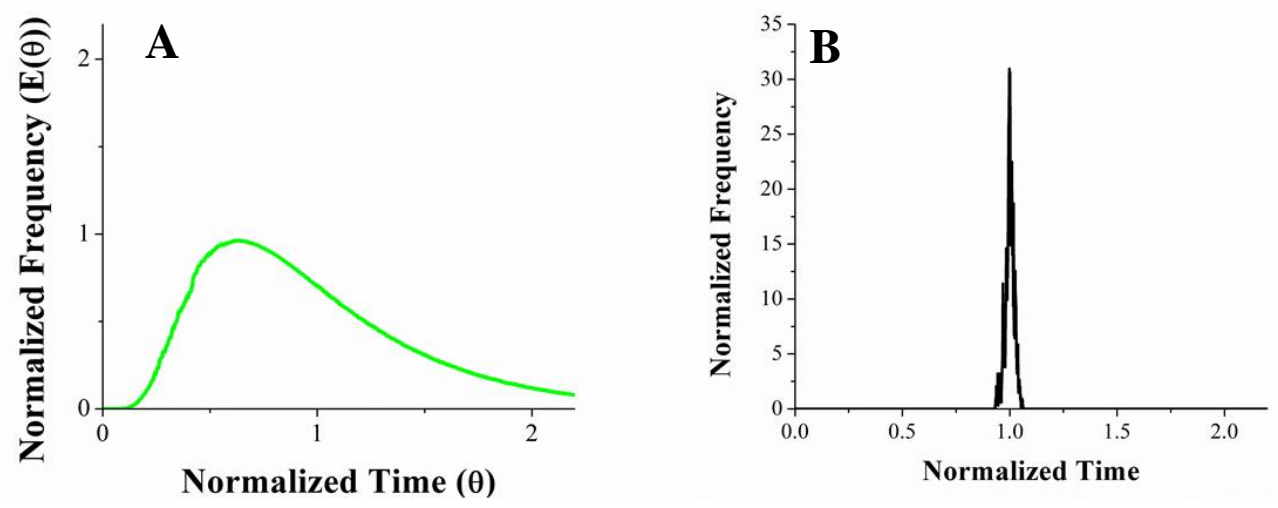

FIGURE 25. (A) RTD AND (B) MEAN AGE CURVE OF MIDDLE PLANE OF N=5.0 VESSEL. 

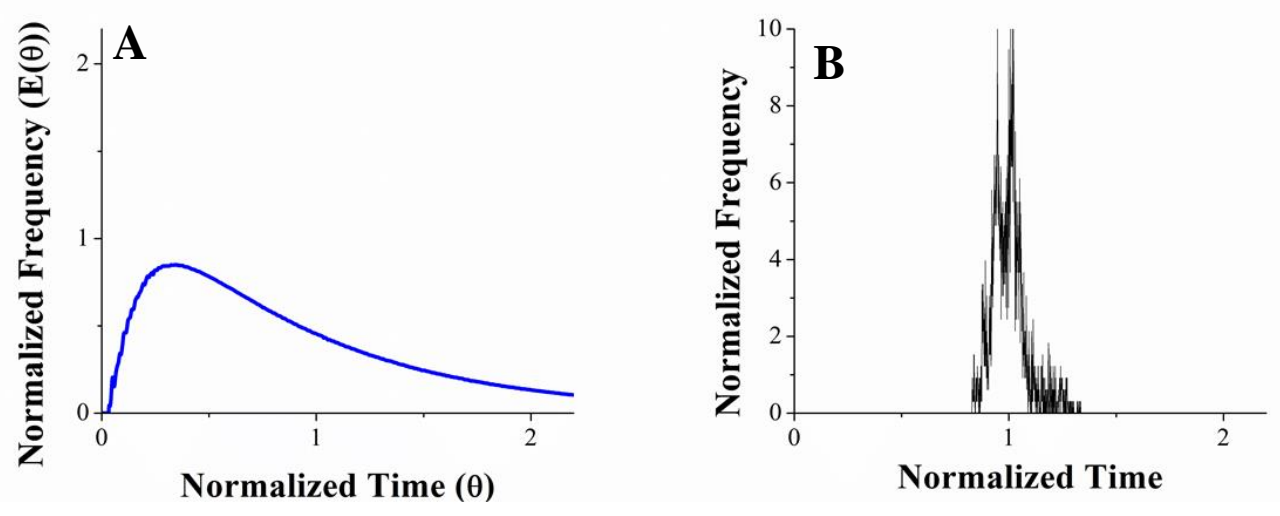

FIGURE 26. (A) RTD AND (B) MEAN AGE CURVE OF LOWEST PLANE OF N=5.0 VESSEL.
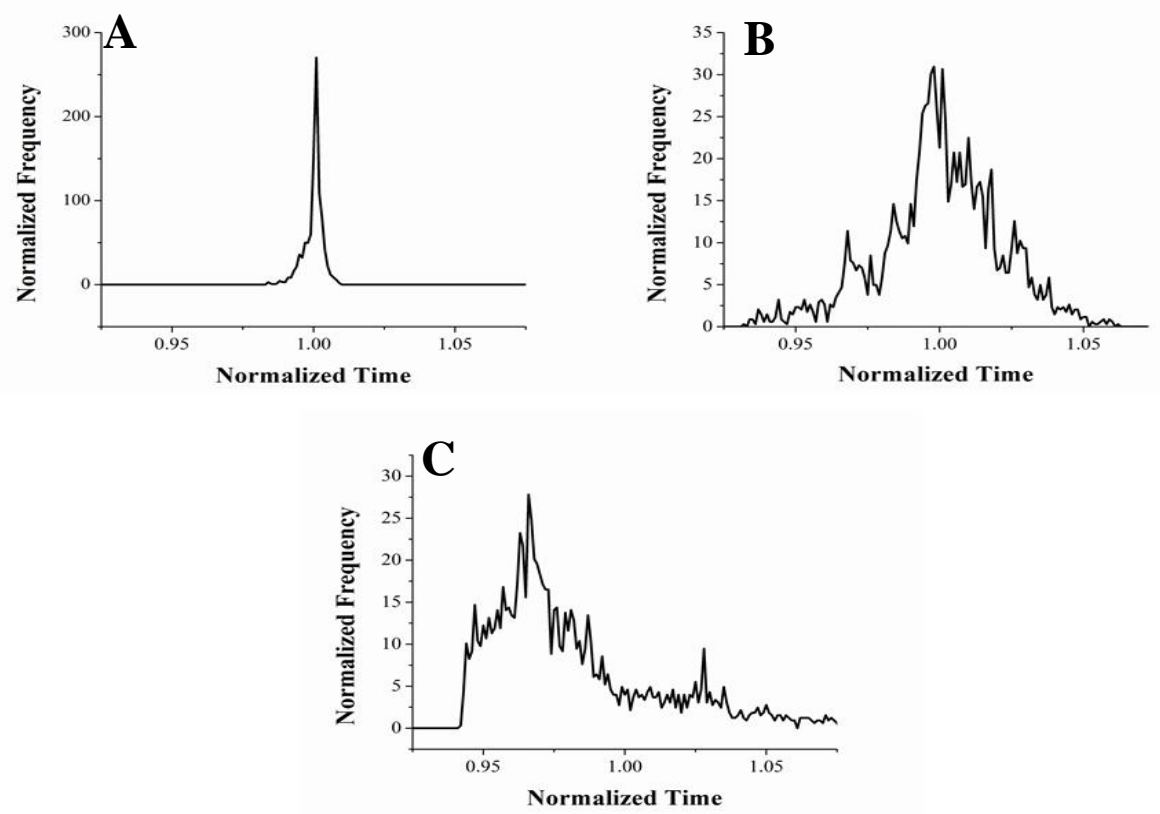

FIGURE 27. COMPARISON OF ZOOMED SECTION OF THE MEAN AGE CURVE ALONG THE LENGTH OF THE N=5.0 VESSEL. (TOP - A, MIDDLE - B, BOTTOM - C). 

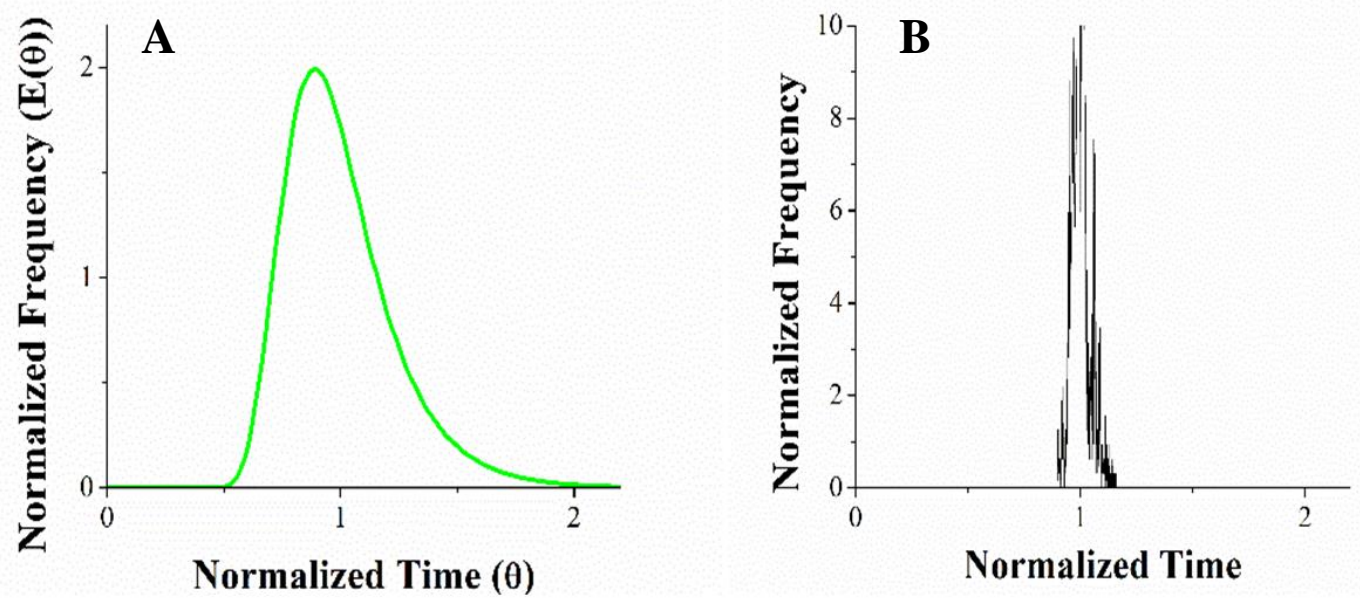

FIGURE 28. (A) RTD AND (B) MEAN AGE CURVE OF HIGHEST PLANE OF $\mathrm{N}=18.9$ VESSEL.
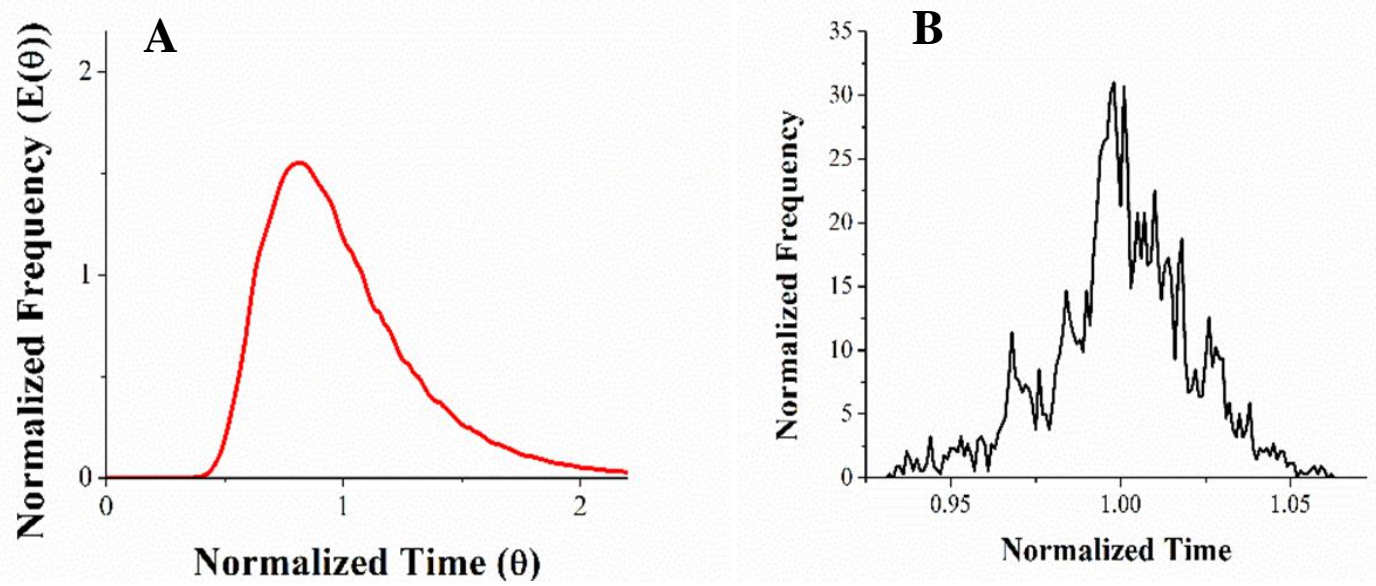

FIGURE 29. (A) RTD AND (B) MEAN AGE CURVE OF MIDDLE PLANE OF $\mathrm{N}=18.9$ VESSEL. 

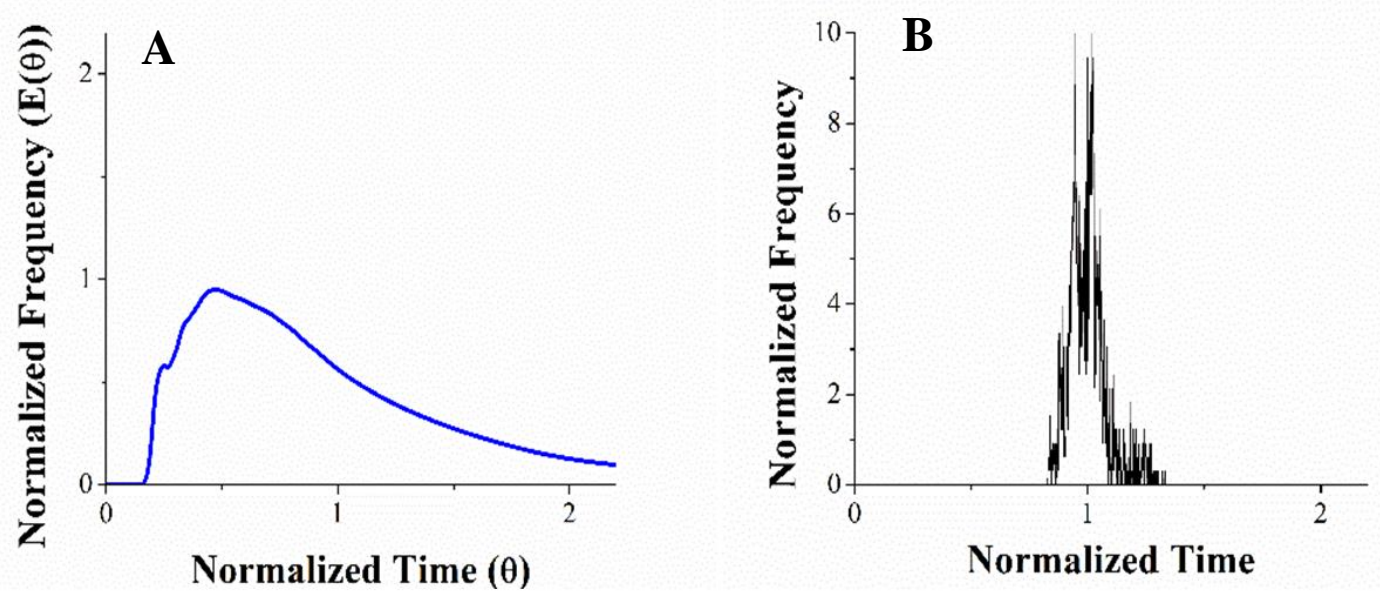

FIGURE 30. (A) RTD AND (B) MEAN AGE CURVE OF LOWEST PLANE OF $\mathrm{N}=18.9$ VESSEL.
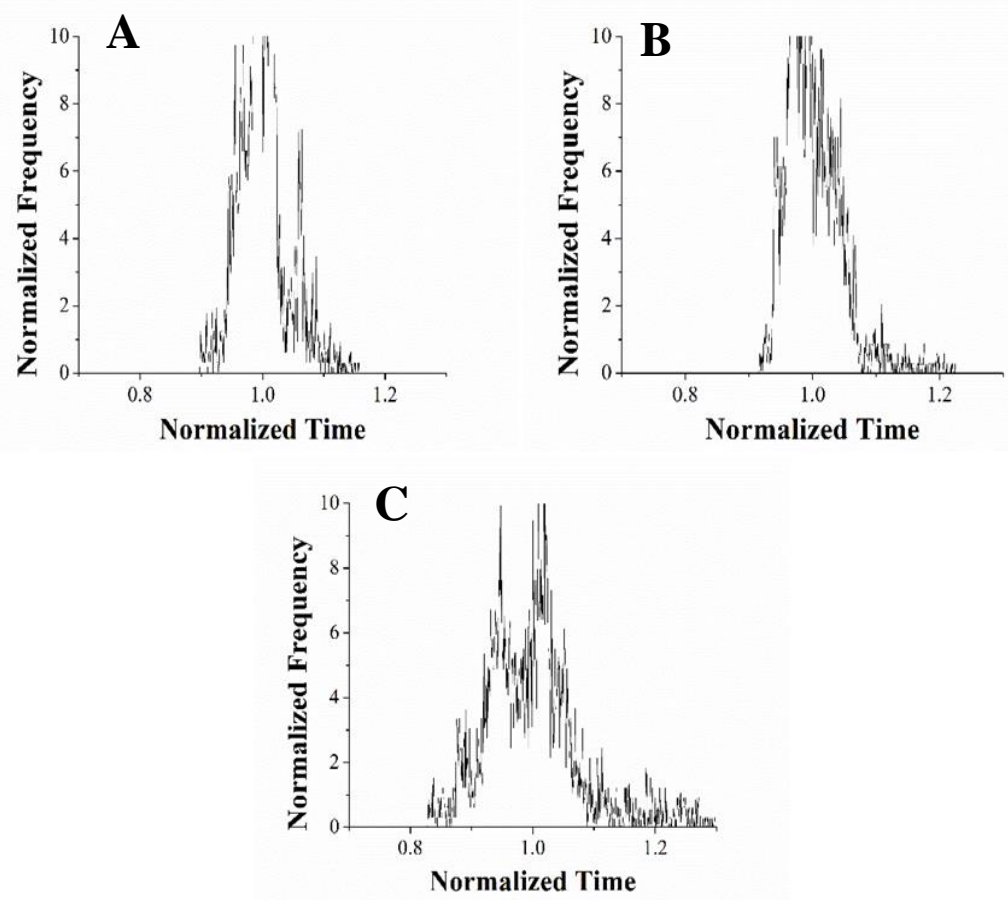

FIGURE 31. COMPARISON OF ZOOMED SECTION OF THE MEAN AGE CURVE ALONG THE LENGTH OF THE N=5.0 VESSEL. (TOP - A, MIDDLE $-\mathrm{B}$, BOTTOM - C). 
Higher mixing (lower $\mathrm{N}$ ) results in broader distributions in mean age. However, the mean age distributions found across these planes are still far more narrow distributions than the RTD curves. A possible explanation could come from theory of CSTRs. In a CSTR (assumed perfect mixing), each entering droplet of fluid is assumed to be equally dispersed throughout the entire fluid region of the vessel as soon as the material enters the reactor. Because of this, the mean age of any certain volume of fluid inside the vessel would be exactly equivalent to the mean, as new fluid will be equally dispersed throughout the reactor. This would explain the narrow distribution demonstrated by mean age curves taken in complex geometries where higher mixing occurs. Instances of this include Liu and Tilton(2010), where a narrow distribution along the flow path along a section with multiple bends and vortices may be observed. This contrasts with Russ and Berson(2016), where they studied RTDs and mean age distributions for multiphase flow (oil/water) in a pipe. Their mean age distributions were generally within $10 \%$ of the experimental and computationally-derived RTDs. Additionally, the larger diameter used by Russ and Berson (2016) (24 inches vs 4 inches used here) could explain why their RTDs and mean age distributions were more similar. Mean age distributions across a larger plane allow for more spatial variation and, hence, wider distributions than seen here.

Degree of mixing changed along the length of the reactor as evidenced by the varying RTD curves. At the first interior measurement plane, both cases show a wellmixed system ( $\mathrm{N}=1.2-1.7)$. This devolves into less-mixed behavior as the fluid moves up the reactor ( $\mathrm{N}$ approaches 3.5-8.5). This can be explained if each impeller is thought of as a stirred tank. As fluid continues to pass through multiple stirred tanks in series, the fluid 
tends towards plug flow behavior as described in Fogler (2006), where a Levenspiel plot shows numerous CSTRs in series approaching plug flow. While this phenomenon has been previously known, experimental demonstration of the behavior has not been well documented due to the impracticality of experimentally measuring RTD's at several locations throughout a long reactor while CFD provides here a perfect platform to demonstrate this. 


\section{CONCLUSIONS}

A comparison of outlet mean age curves and RTDs for various levels of mixing was performed for a stirred tubular reactor. Tanks in series model, N, was used to characterize mixing. Multiple levels of mixing were achieved by varying inlet mass flow rate and impeller rotation speed.

Mean age distributions remained narrow for all levels of mixing, particularly at the reactor outlet, but also along the length of the reactor. This phenomenon was explained by the high agitation resulting from a 90 degree turn with a contraction forcing the mean age to aggregate towards the mean, losing the distribution. This was mitigated slightly when interior RTDs and mean age curves were investigated; however, the distribution was still far narrower than the RTD curves in the same area. This same effect has been reported in literature.

RTD curves exhibited well mixed characteristics near the entrance of the reactor and approached plug flow characteristics further along the reactor length. Figures 4.20-22 show this trend, backed by Fogler (2006). 
There was a larger than expected discrepancy between the average outlet mean age and the mean residence time, especially in low $\mathrm{N}$ cases. Mean age times were consistently less than mean times derived from RTDs. The averaging effect of high mixing explains this problem. At high mixing levels, the large tail drives the mean residence time further from the peak, where the averaging of the mean age loses the tail, keeping the average mean age far closer to the peak.

Ultimately, the value in generating mean age was found to be in the spatial distribution of age over the entire vessel, not as an outlet distribution. Plus, mean age is calculated at steady state, which is significantly more computationally efficient. RTDs and mean age measurements are two independent techniques to evaluate mixing within fluid systems; RTDs provide a measure of overall mixing and mean age provides a measure of local mixing. 


\section{RECOMMENDATIONS}

To expand upon this experiment, an investigation into the averaging effect on local mixing of mean age could be performed. To accomplish this, a pipe with a significant compression area could be used. Cross sectional planes would be drawn along the length of the pipe, allowing for measurement of distributions of mean age before and after a section of intense local mixing. The distributions before the compression zone would be expected to appear very similar to the RTD measured against them, where any planar mean age distributions following the area of high local mixing would be expected to appear as far narrower distributions, especially when compared to the RTD. Additionally, a measurement of the required length of pipe before planar mean age distributions return to a certain variance and agreement with RTDs could be conducted in the same system. Further forms of heightened local mixing and their effects on spatial mean age distributions could be investigated. 


\section{REFERENCES}

1. Danckwerts, P. V., The effect of incomplete mixing on homogeneous reactions. Chemical Engineering Science 1959, 8 (1), 93-102.

2. Baleo, J. N.; Le Cloirec, P., Numerical simulation of the spatial distribution of mean residence time in complex flows through porous media. Prog Theor Phys Supp 2000, (138), 690-695.

3. Liu, M.; Tilton, J. N., Spatial Distributions of Mean Age and Higher Moments in Steady Continuous Flows. Aiche J 2010, 56 (10), 2561-2572.

4. Russ, D. C.; Berson, R. E., Mean age theory in multiphase systems. Chemical Engineering Science 2016, 141, 1-7.

5. Danckwerts, P. V., Continuous flow systems: Distribution of residence times. Chemical Engineering Science 1953, 2 (1), 13.

6. Klutz, S.; Kurt, S. K.; Lobedann, M.; Kockmann, N., Narrow residence time distribution in tubular reactor concept for Reynolds number range of 10-100. Chem Eng Res Des 2015, 95, 22-33.

7. Sugiharto, S.; Su'ud, Z.; Kurniadi, R.; Wibisono, W.; Abidin, Z., Radiotracer method for residence time distribution study in multiphase flow system. Appl Radiat Isotopes 2009, 67 (7-8), 1445-1448. 
8. Fogler, H. S., Elements of Chemical Reaction Engineering. 4 ed.; Pearson: Boston, MA, 2006.

9. Zwietering, T. N., The degree of mixing in continuous flow systems. Chemical Engineering Science 1959, 11 (1), 1-15.

10. Spalding, D. B., A note on mean residence-times in steady flows of arbitrary complexity. Chemical Engineering Science 1958, 9 (1), 74-77.

11. Sandberg, M., What Is Ventilation Efficiency. Build Environ 1981, 16 (2), 123-

12. Kusunoki, K., Mixing and Reaction of Liquids Flowing in Special Circular Tubes. Chemical engineering 1965, 29 (1), 8-14.

13. Levenspiel, O., Chemical Reaction Engineering. 3 ed.; Wiley: 1999; p 668.

14. Zhang, G. T.; Wannenmacher, N.; Haider, A.; Levenspiel, O., How to Narrow the Residence Time Distribution of Fluids in Laminar-Flow in Pipes. Chem Eng J Bioch Eng 1990, 45 (1), 43-48.

15. Schlossmacher, E. J.; Weinstein, H.; Lochaya, S.; Shaffer, A. B., Perfect mixers in series model for fitting venoarterial indicator-dilution curves. Journal of Applied Physiology 1967, 22, 327-332.

16. Katoh, T.; Tokumura, M.; Yoshikawa, H.; Kawase, Y., Dynamic simulation of multicomponent gas separation by hollow-fiber membrane module: Nonideal mixing flows in permeate and residue sides using the tanks-in-series model. Sep Purif Technol 2011, 76 (3), 362-372.

17. Nautiyal, A.; Chyang, C.-S.; Li, P.-W.; Hou, H.-Y., Horizontal gas mixing in rectangular fluidized bed: A novel method for gas dispersion coefficients in various 
conditions and distributor designs. Chinese Journal of Chemical Engineering 2017, 25 (6).

18. Abdulmohsin, R. S.; Al-Dahhan, M. H., Axial dispersion and mixing phenomena of the gas phase in a packed pebble-bed reactor. Ann Nucl Energy 2016, 88, 100-111.

19. Bartak, M.; Beausoleil-Morrison, I.; Clarke, J. A.; Denev, J.; Drkal, F.; Lain, M.; Macdonald, I. A.; Melikov, A.; Popiolek, Z.; Stankov, P., Integrating CFD and building simulation. Build Environ 2002, 37 (8-9), 865-871.

20. Chanteloup, V.; Mirade, P. S., Computational fluid dynamics (CFD) modelling of local mean age of air distribution in forced-ventilation food plants. $J$ Food Eng 2009, 90 (1), 90-103.

21. Liu, M. Y., Quantitative Characterisation of Mixing in Stirred Tank Reactors with Mean Age Distribution. Can J Chem Eng 2011, 89 (5), 1018-1028.

22. Liu, M. Y., Prediction of Tracer Concentration and Mixing in CFSTRs with Mean Age Distribution. Ind Eng Chem Res 2011, 50 (9), 5838-5851.

23. Liu, M. Y., Age distribution and the degree of mixing in continuous flow stirred tank reactors. Chemical Engineering Science 2012, 69 (1), 382-393.

24. Kopal, Z. k., Tables on supersonic flow around cones. 1 ed.; Cambridge: Massachusetts, 1947; p 555.

25. Blottner, F. G., Chemical nonequilibrium boundary layer. AIAA Journal 1964, 2 (2), 232-240.

26. Blottner, F. G.; MISSILE, G. E. C. P. P.; DIV., S., Nonequilibrium Laminar Boundary Layer Flow of Ionized Air. Defense Technical Information Center: 1964. 
27. Hall, H. G.; Eshcenroeder, A. Q.; Marrone, P. V., Blunt-Nose Inviscid Airflows with Coupled Nonequilibrium Processes. Journal of the Aerospace Sciences 1962, 29 (9), 1038-1051.

28. Bhaskaran, R.; Collins, L. Introduction to CFD Basics: Cornell University.

29. Wang, H. B.; Sun, M. B.; Yang, Y. X.; Qin, N., A passive scalar-based method for numerical combustion. Int J Hydrogen Energ 2015, 40 (33), 10658-10661.

30. Holzer, Mark; Orbe, Clara; Primeau, François W. Stratospheric mean residence time and mean age on the tropopause; Connections and implications for observational constraints. Journal of Geophysical Research: Atmospheres. 2012 
VITA

Nolan Theaker was born in Danville, KY in 1994. He graduated from Boyle County High School in 2012. Following this, he attended the University of Louisville Speed School of Engineering where he received a B.S. in Chemical Engineering in 2016. Currently, he is a Masters of Engineering student at the University of Louisville, expecting to complete this degree in 2017. Following this, he will begin employment at the University of North Dakota Institute for Energy Research. His research focuses on energy and CFD research. 